\title{
Surgery for nonsmall cell lung cancer
}

\author{
Loïc Lang-Lazdunski
}

\author{
Number 3 in the Series "Topics in Thoracic Oncology" \\ Edited by G. Zalcman and N. Girard
}

\begin{abstract}
Affiliations: Dept of Thoracic Surgery, Guy's Hospital, London, and Division of Cancer Studies, King's College London, London, UK.

Correspondence: L. Lang-Lazdunski, Dept of Thoracic surgery, 6th Floor Borough Wing, Guy's Hospital, London SE1 9RT, UK. E-mail: loic.lang-lazdunskidgstt.nhs.uk
\end{abstract}

ABSTRACT Surgery remains the best curative option in patients with early stage lung cancer (stage I and II). Developments in minimally invasive techniques now allow surgeons to perform lung resections on elderly patients, patients with poor pulmonary function or significant cardiopulmonary comorbidities. New techniques, such as stereotactic radiotherapy and ablative procedures, are being evaluated in early-stage lung cancer and may represent an alternative to surgery in patients unfit for lung resection. Perioperative mortality rates have dropped significantly at most institutions in the past two decades and complications are managed more efficiently. Progress in imaging and staging techniques have helped cut futile thoracotomy rates and offer patients the most adequate treatment options. Large randomised trials have helped clarify the role of neoadjuvant, induction and adjuvant chemotherapy, as well as radiotherapy. Surgery remains an essential step in the multimodality therapy of selected patients with advanced-stage lung cancer (stage III and IV). Interventional and endoscopic techniques have reduced the role of surgery in the diagnosis and staging of nonsmall cell lung cancer, but surgery remains an important tool in the palliation of advanced-stage lung cancer. Large national/international surgical databases have been developed and predictive risk-models for surgical mortality/morbidity published by learned surgical societies. Nonetheless, lung cancer overall survival rates remain deceptively low and it is hoped that early detection/screening, better understanding of tumour biology and development of biomarkers, and development of efficient targeted therapies will help improve the prognosis of lung cancer patients in the next decade.

0

@ERSpublications

Despite progress in surgical techniques, radiotherapy techniques and targeted therapy, lung cancer prognosis remains poor http://ow.ly/mXV3x

\section{Introduction}

Lung cancer is the most common cancer in the world and remains the most common cause of cancerrelated death: more than 1.35 million deaths per annum worldwide and more than 350000 deaths per annum in Europe $[1,2]$. The 1-year survival rates vary significantly from one country to another ranging from approximately $30 \%$ in the UK to $46 \%$ in Sweden [2]. Approximately $85 \%$ of lung cancers are nonsmall cell lung cancers (NSCLCs) and only $25-30 \%$ of these are eventually suitable for surgical resection with a curative intent [3]. At present, the 5-year survival of patients who have their NSCLC resected ranges between $\sim 75 \%$ for stage Ia and $25 \%$ for stage IIIa [3].

Previous articles in this series: No 1: Girard N. Thymic epithelial tumours: from basic principles to individualised treatment strategies. Eur Respir Rev 2013; 22: 75-87. No 2: Dooms C, Muylle I, Yserbyt J, Ninane V. Endobronchial ultrasound in the management of nonsmall cell lung cancer. Eur Respir Rev 2013; 22: 169-177.

Received: May 202013 | Accepted after revision: June 102013

Conflict of interest: Disclosures can be found alongside the online version of this article at err.ersjournals.com

Provenance: Submitted article, peer reviewed.

Copyright @ERS 2013 
The current treatment strategy for NSCLC depends on clinical staging. Surgical resection is generally considered the treatment of choice in patients with stage I and II disease whose performance status allows for general anaesthesia and a lung resection [3-5]. Surgery is also an accepted treatment modality in a fair proportion of patients with clinical stage IIIa disease, and in a small proportion of selected patients with stage IIIb and stage IV disease. Although the standards of resections have changed little over the past 20 years, there have been a number of advances in staging, perioperative and anaesthetic management, as well as some noticeable progress made in surgical techniques and approaches.

Lung cancer surgery began with the first successful pneumonectomy reported by Graham and Singer in 1933 [6]. Lobectomies and segmentectomies were reported in the 1940s and 1950s and the first successful sleeve lobectomy for carcinoma in 1952 [7, 8]. The introduction and development of surgical sutures and staplers made lung resection safer, faster and less traumatic, while maintaining surgical oncologic principles. With surgeons gaining experience and confidence in lung resections and thoracic anaesthesia progressing, specialised thoracic units developed and surgeons started extending cancer resections to the chest wall and great vessels [9]. The importance of lymph node involvement (hilar and mediastinal stations) in the prognosis of lung cancer was recognised [10]. The advent of video-assisted thoracic surgery (VATS) in the 1990s considerably changed the approach to early-stage lung cancer [11-13], as well as malignant pleural effusions. New techniques, such as radiofrequency ablation (RFA) or stereotactic body radiation therapy (SBRT), are now offered as an alternative to surgery in patients unfit for lung resection [5, 14]. More recently, robotic approaches have been proposed in order to reduce the operative trauma, facilitate the surgical procedure and reduce the length of hospital stay [15]. All these techniques have yet to be validated and are currently being compared to conventional surgery in prospective randomised trials $[5,16]$.

\section{Clinical and surgical staging}

The treatment and prognosis of a lung cancer depend largely on the stage of advancement at the time of diagnosis. The importance of hilar and mediastinal lymph node involvement has long been recognised as an important prognostic factor in lung cancer [17]. The actual classification of lymph nodes combines the features of the first proposed classification (Naruke), advocated by the American Joint Committee on Cancer Staging, and of the second classification: the nodal map proposed by the American Thoracic Society. All N2 nodes are contained within the mediastinum, under the mediastinal pleura and numbered 1-9. It is, however, recognised that in many patients, the mediastinal pleural reflection can be difficult to identify intraoperatively and so the distinction between hilar nodes (N1) and low tracheobronchial nodes (N2) may be difficult to make.

The International Association for the Study of Lung Cancer (IASLC) recognised the importance of staging in the prognosis and treatment of lung cancer and Clifton Mountain and colleagues were the first to propose a logical classification of lung cancer, based on a database of patients operated on at MD Anderson Cancer Center [18].

The TNM (tumour, node, metastasis) classification has been amended on several occasions and amendments have been proposed recently based on a large international database (tables 1 and 2) [18].

At present, it seems totally inappropriate to operate on a patient with a suspected diagnosis of lung cancer without a proper staging.

A chest radiograph and computed tomography (CT) are often performed in the first instance, when a lung cancer is suspected. Not infrequently, chest radiography performed for other reasons (preoperative setting, general anaesthesia, routine exam, screening) will show a lung mass. CT is the initial modality of choice for diagnosis and staging of suspected lung cancer and will help determine the most appropriate further investigations [19]. Tissue diagnosis can be obtained by CT or ultrasound-guided biopsy in more than $90 \%$ of patients when the mass is peripherally located and percutaneously accessible [20]. Alternatively, centrally located lesions can be reached through bronchoscopy. Alternatives include obtaining tissue from enlarged supraclavicular lymphadenopathy (fine needle aspiration) or from mediastinal or hilar lymphadenopathy through endobronchial ultrasound (EBUS)-guided aspiration. It is important to understand that a negative result does not rule out malignancy and if the findings are thought to be unsatisfactory, the biopsy must be repeated. Eventually, if all noninvasive techniques fail, a surgical biopsy can be discussed (open approach or video thoracoscopy).

Once the diagnosis of NSCLC has been established, it is imperative to stage the N and M factors. Staging starts with a good and complete physical examination, particularly palpation of supraclavicular fossae, axillae and neck to rule out supraclavicular, axillary or cervical lymphadenopathy. At present, it is recommended that all patients considered for active treatment have a positron emission tomography (PET)-CT. A number of small studies have showed that PET-CT is superior to CT or PET alone in lung cancer staging [19]. In most patients, it will help diagnose or rule out distant metastases, as well as show positive 


\section{TABLE 1 TNM (tumour, node, metastasis) classification for lung cancer}

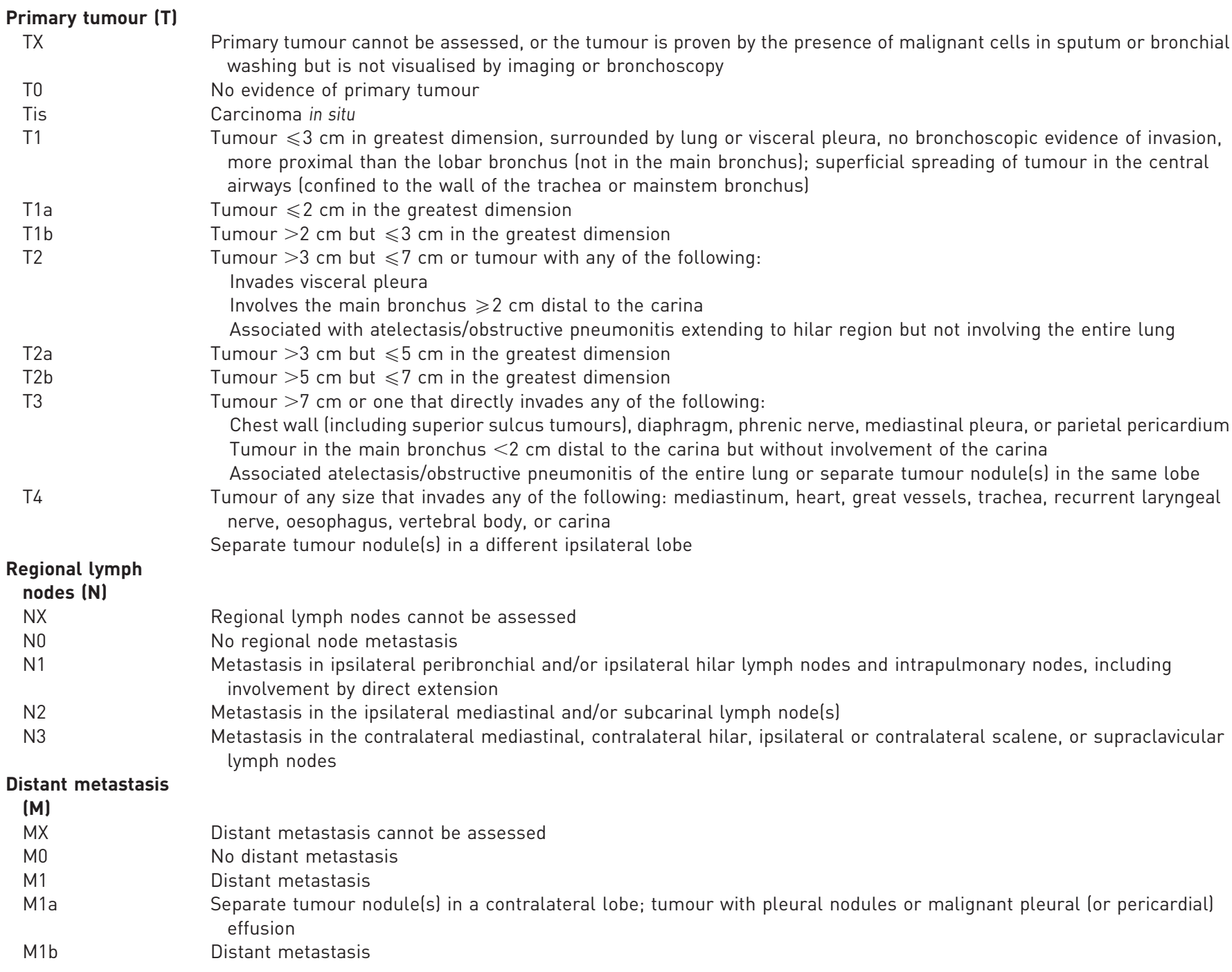

Reproduced from [18] with permission from the publisher.

or negative lymph nodes. Limitations of PET-CT include small tumours $(<8 \mathrm{~mm})$, low metabolic activity of tumour (i.e. bronchioloalveolar carcinoma), breathing artefacts, uncontrolled glycaemia, local inflammation or lung collapse (lobar atelectasis or lung collapse) [19]. In addition to the anatomic information, PET-CT can provide metabolic information linked to prognosis. BERGHMANs et al. [21] showed that tumours with an increased metabolic activity measured by maximal standardised uptake value have a worse prognosis.

Mediastinoscopy is still considered the gold standard in many institutions to investigate mediastinal lymph nodes. However, mediastinoscopy does not allow access to lymph node stations 8, 9 and 10. In addition, an anterior approach is necessary for reaching stations 5 and 6: mediastinotomy or extended cervical mediastinoscopy $[22,23]$. Recently, the development of EBUS transbronchial needle aspiration or endooesophageal ultrasound-guided needle aspiration (EUS) has allowed for more accurate staging of proximal hilar and all mediastinal stations $[24,25]$. As chest CT, PET-CT or PET scan do not have a specificity, negative predictive value or accuracy of $100 \%$, it is recommended that patients with negative lymph nodes on PET or PET-CT, but enlarged nodes on staging CT still undergo proper staging of mediastinal nodes through EBUS/EUS or mediastinoscopy, before thoracotomy [26, 27]. Again, if results remain inconclusive, a surgical biopsy (VATS preferably) may help stage mediastinal lymph nodes accurately.

Brain CT or magnetic resonance imaging (MRI) should be performed in any patient with lung cancer presenting with abnormal neurology. The prevalence of brain metastases may be influenced by both TNM 
TABLE 2 Anatomic stage/prognostic groups

\begin{tabular}{|c|c|c|c|}
\hline Stage & $T$ & $\mathbf{N}$ & $M$ \\
\hline \multirow[t]{2}{*}{ la } & T1a & No & MO \\
\hline & $\mathrm{T} 1 \mathrm{~b}$ & NO & MO \\
\hline lb & T2a & No & MO \\
\hline \multirow[t]{4}{*}{ Ila } & T1a & N1 & MO \\
\hline & $\mathrm{T} 1 \mathrm{~b}$ & N1 & MO \\
\hline & T2a & $\mathrm{N} 1$ & MO \\
\hline & $\mathrm{T} 2 \mathrm{~b}$ & No & MO \\
\hline \multirow[t]{2}{*}{ IIb } & $\mathrm{T} 2 \mathrm{~b}$ & N1 & MO \\
\hline & T3 & No & MO \\
\hline \multirow[t]{6}{*}{ IIla } & $\mathrm{T} 1$ & N2 & MO \\
\hline & T2 & N2 & MO \\
\hline & T3 & N2 & MO \\
\hline & T3 & N1 & MO \\
\hline & T4 & NO & MO \\
\hline & $\mathrm{T} 4$ & N1 & MO \\
\hline \multirow[t]{5}{*}{ IIIb } & T4 & N2 & MO \\
\hline & $\mathrm{T} 1$ & N3 & MO \\
\hline & $\mathrm{T} 2$ & N3 & MO \\
\hline & T3 & N3 & MO \\
\hline & $\mathrm{T} 4$ & N3 & MO \\
\hline IV & $\mathrm{T}$ any & $\mathrm{N}$ any & M1a or $1 b$ \\
\hline
\end{tabular}

T: tumour; N: node; M: metastasis. Reproduced from [18] with permission from the publisher.

stage and cell type [19]. Some have suggested that brain CT or MRI should be performed routinely in the staging of lung cancer as up to $10 \%$ of patients have asymptomatic brain metastases [19]. MRI detects more and smaller lesion than contrast CT [28]. Although routine brain CT or MRI cannot be recommended in all patients with potentially resectable NSCLC, it seems reasonable to recommend preoperative MRI in asymptomatic patients with stage III disease [19].

Adrenal lesions are commonly diagnosed on CT. The likelihood of metastasis increases with TNM stage of the primary tumour and adrenal lesion size. PET and PET-CT currently represent the most reliable test to differentiate between a benign lesion and a metastasis [29]. Similarly, PET is more sensitive than conventional bone scintigraphy in detecting bone metastases [30]. PET-positive lesions should be biopsied if any doubt persists and patients with potentially resectable lung cancer should not be denied a potentially curative treatment on the basis of a PET-positive lesion only [19].

\section{Assessment of the risk for surgery}

Although a large number of patients could not be offered surgery due to age or comorbidities in the past, the progress in thoracic anaesthesia, perioperative medicine and surgical techniques now allow octogenarians and patients with significant cardiopulmonary comorbidities to undergo lung resections routinely [31]. The estimation of in-hospital death and complications is of paramount importance to decide whether a patient should be offered surgery or not and to inform the patient in the best possible way. In hospital death after lobectomy for lung cancer in the UK was reported as $2.6 \%$ in 2003 [32] and has now reduced to $2.3 \%$. The 30-day mortality for pneumonectomy in the National Lung Cancer Audit (UK) was $5.8 \%$ and the in-hospital mortality for pneumonectomy was $5.6 \%$ over the period $2002-2007$ in the Society of Thoracic Surgeons (STS) database [33].

Risk stratification for death in thoracic surgery remained relatively basic until recently [19]. The European Society of Thoracic surgeons (ESTS) risk model had 3426 patients with 66 deaths and the Veterans Affairs risk model had 3516 patients with 184 deaths $[34,35]$. More recently, the French Society of Thoracic and Cardiovascular Surgery [36] and the STS have produced risk-adjustment models to identify predictors of mortality and major complications after lung resections [37], based on databases including $>15000$ patients each. These models may be used to inform clinical decisions and to compare risk-adjusted outcomes for quality improvement purposes.

All patients considered for a lung resection should have an ECG and full lung function testing, including diffusing capacity of the lung for carbon monoxide (DLCO), and spirometry, including forced expiratory 
volume in $1 \mathrm{~s}$ (FEV1) and forced vital capacity (FVC) [19]. Any significant history of cardiac disease should lead to the performance of an echocardiogram, a stress-echocardiogram or a coronary angiogram. Myocardial infarction is a major cause of mortality after non-cardiac surgery [19]. The risk of cardiac death or non-fatal myocardial infarction associated with lung resection is generally $1-5 \%$ and is ranked as intermediate risk by the 2007 American College of Cardiology/American Heart Association (ACC/AHA) guidelines on cardiovascular evaluation before non-cardiac surgery [38]. The 2007 ACC/AHA guidelines should be used to estimate the perioperative cardiovascular risk. Lung resection should be avoided within 30 days of myocardial infarction, as it can result in prohibitive mortality [19]. Patients with less than two risk factors and good cardiac function can proceed to surgery without further investigations. Patients with greater than three risk factors or poor cardiac function should be reviewed by a cardiologist [19]. It is recommended that medical therapy is optimised as early as possible before surgery in patients with ischaemic heart disease and that anti-ischaemic treatment including aspirin, statins and $\beta$-blockers is continued in the perioperative period [19]. Coronary stenting or surgical revascularisation should be discussed with a cardiologist prior to thoracic surgery in patients with stable angina [19].

Evaluation of lung function is important to estimate the risk of in-hospital mortality (respiratory failure) and the impact of the lung resection on quality of life (i.e. long-term dyspnoea, permanent oxygen therapy). As a general rule, it was accepted that a FEV1 of $40 \%$ of the predicted value was the cut-off for offering lung resection [39]. However, several studies have shown that transfer factor is also an important predictor of postoperative morbidity despite normal spirometry [40]. A predicted postoperative FEV1 or DLCO $<40 \%$ predicted indicates an increased risk of perioperative complications, including death, following lung cancer resection [41]. Different techniques have been used to predict postoperative lung function including quantitative ventilation and perfusion scintigraphy, quantitative CT scanning and dynamic perfusion MRI [42]. A range of cardiopulmonary exercise tests have been routinely used by thoracic surgeons to help predict the risk of postoperative dyspnoea. These include stair climbing (usually two flights of stairs), 6 and 12 min walk tests, shuttle walk test and formal cardiopulmonary exercise testing with measurement of maximal oxygen uptake $\left(V^{\prime} \mathrm{O}_{2} \max \right)$ [41]. The risk of perioperative complications and death can be stratified by $V^{\prime} \mathrm{O}_{2}$ max. Patients with a $V^{\prime} \mathrm{O}_{2} \max >20 \mathrm{~mL} \cdot \mathrm{kg}^{-1} \cdot \mathrm{min}^{-1}$ are not at increased risk of complications or death; $V^{\prime} \mathrm{O}_{2} \max <15 \mathrm{~mL} \cdot \mathrm{kg}^{-1} \cdot \mathrm{min}^{-1}$ indicates an increased risk of perioperative complications and $V^{\prime} \mathrm{O}_{2} \max$ $<10 \mathrm{~mL} \cdot \mathrm{kg}^{-1} \cdot \mathrm{min}^{-1}$ indicates a very high risk of perioperative complications and death [41]. Typically, patients who cannot climb a flight of stairs have a $V^{\prime} \mathrm{O}_{2} \max$ of $10 \mathrm{~mL} \cdot \mathrm{kg}^{-1} \cdot \mathrm{min}^{-1}$. Desaturation during exercise has been associated with an increased risk of perioperative complications as well [41]. All these tests need to be interpreted carefully and the surgeon has to take into account other anatomical factors such as the weight and size of patients, the presence of a shunt and the presence of correctible emphysema. Anecdotal experience suggests that patients with very poor lung function can tolerate lung resection when combined lung volume reduction is associated. This is particularly true in patients with severe heterogeneous emphysema, particularly emphysema limited to the lobe containing the cancer [41]. In those patients, it seems reasonable to use the criteria used to select patients for lung volume reduction surgery, with a lower limit of preoperative FEV1 or DLCO $>20 \%$ predicted [19].

Postoperative lung function is estimated by the method of segment counting [39]. The total number of segments is 19 (9 left, 10 right). The number of segments obstructed $(\mathrm{O})$ is measured by imaging (chest CT) and subtracted from 19 to obtain the number of functioning segments $(\mathrm{T}): \mathrm{T}=19-\mathrm{O}$. The residual number of segments $(\mathrm{R})$ is estimated as: $\mathrm{R}=\mathrm{T}$-functioning segments to be resected. Typically, the number of segments per lobe is: right upper lobe $n=3$, middle lobe $n=2$, right lower lobe $n=5$, left upper lobe $n=5$, left lower lobe $n=4$. The predicted postoperative (ppo) lung function is estimated by:

$$
\text { ppo }=(\text { preoperative value } / \mathrm{T}) \cdot \mathrm{R}
$$

\section{Types of procedures and approaches}

Pneumonectomy is the largest lung resection possible. It consists of the resection of a whole lung. It is mostly used in patients with central tumours, involvement of a mainstem bronchus, left or right pulmonary artery, and both superior and inferior pulmonary vein. Pneumonectomy used to account for $\sim 30 \%$ of lung resections for cancer in thoracic units until the 1990s. Mortality, morbidity and complications of pneumonectomies are well recognised. Left pneumonectomy is usually better tolerated than right pneumonectomy and some authors went on to say that "the right pneumonectomy was a disease in itself" (J. Deslauriers). The mortality associated with pneumonectomy remains significant (5-10\%) and the right pneumonectomy carries a higher risk of death or complications than the left pneumonectomy, mainly attributable to bronchopleural fistula [33, 37, 43].

Many studies have now clearly shown that, when feasible, sleeve resections are valid alternatives to pneumonectomy as they result in lower perioperative mortality and better mid-term survival with excellent 
long-term outcomes [44-46]. Sleeve resections can involve the bronchial tree only or the ipsilateral pulmonary artery as well ("double sleeve or bronchovascular resection") [45, 47]. The perioperative mortality has been reported as $1.5-4 \%$ at most institutions. The increasing use of induction treatments (chemotherapy or chemoradiotherapy), has allowed for a further reduction in pneumonectomy rates by allowing significant downstaging of large hilar tumours [44]. Consequently, pneumonectomy rates are now down to represent $10-15 \%$ of lung resections for primary lung cancer in most specialised thoracic units.

Lobectomy consisting of the surgical removal of a pulmonary lobe (upper, middle or lower) remains the gold standard for most patients with an operable lung cancer and accounts for $\sim 60-70 \%$ of lung resections in most specialized thoracic units. The associated mortality is between 2 and 3\% in most units [32, 35].

Its variant bilobectomy is performed exclusively for right lung cancers (right upper and middle lobectomy, or right middle and lower lobectomy). It is performed when the all superior pulmonary vein has to be sacrificed, when tumour or lymphadenopathy involve the bronchus intermedius, when the pulmonary artery is infiltrated in the fissure, or when the tumour crosses the major or minor fissure [48]. The mortality associated with bilobectomy is equivalent to the one after lobectomy, but the morbidity is higher and up to $71 \%$ of patients experienced complications in recent series $[49,50]$.

There are 10 pulmonary segments in the right lung and nine pulmonary segments in the left lung. Segmental bronchi and vessels can be individualised and divided (ligated, or stapled). The segmental plan is more difficult to find and is incomplete in most patients, resulting in significant air leaks. Therefore, nowadays many surgeons will ventilate the lung following division of the segmental bronchus in order to find the limit of the segment and place a stapler over the presumed segmental plan in order to expedite the procedure and minimise postoperative air leaks. It is recommended that the stapler is placed a few millimetres beyond the presumed segmental fissure, extending to the adjacent segment, in order to include the intersegmental lymphatic drainage of the involved segment in the resection ("extended segmentectomy").

The main segmentectomies used at present are: the apical lower segmentectomy (segment 6); the lingulectomy (segment 4 and 5, left lung) equivalent to a middle lobectomy; the culmenectomy (segment 1, 2 and 3, left lung); and the basal segmentectomy (segments 7-10, right lung, or segments 8-10 left lung). As a segment represents a true anatomic entity in the lung with its own blood supply, bronchus and lymphatic drainage, segmentectomy could be regarded as an oncologically valid procedure in patients with small tumours strictly limited to a segment, whose lung function would not allow for a lobectomy.

Wedge resections are non-anatomic resections consisting in the surgical removal of the lung tumour with a surgical margin as wide as possible to minimise the risk of local recurrence. It is recognised that wedge resection does not constitute an adequate lung cancer operation in most patients with lung cancer, but this may represent an acceptable option in patients with poor pulmonary function and no other alternative, or in Asian patients with multiple peripheral ground-glass type adenocarcinomas $<20 \mathrm{~mm}[19,51,52]$. In the absence of data proving the benefit of wedge resections, these procedures should be avoided as much as possible and the surgeon should always try to perform a systematic lymph node dissection concomitantly in order to obtain an adequate staging.

No matter the type of lung resection considered or performed, it is recommended that pleural lavage cytology is performed routinely in all patients undergoing lung resection for lung cancer [53]. This allows for a more accurate TNM staging, prognosis and, eventually, adjustment of adjuvant therapy.

\section{Extended lymphadenectomy versus lymph node sampling}

The role of routine hilar and mediastinal lymphadenectomy versus lymph node sampling remains controversial and the extent of lymph node tissue excised at surgery varies considerably from one thoracic unit to another $[54,55]$. A large randomised trial comparing these modalities for patients with N0 or N1 disease is ongoing. At present, the IASLC and ESTS recommend that an adequate mediastinal lymphadenectomy should include exploration and excision of lymph nodes from stations $2 \mathrm{R}, 4 \mathrm{R}, 7,8$ and 9 for right-sided cancers and stations 4L, 5, 6, 7, 8 and 9 for left-sided cancers [56]. Three hilar and three interlobar lymph nodes should be excised as well to result in an adequate resection [56].

\section{Surgery for early stage lung cancer (stage I and II)}

Surgery is the treatment of choice for patients with stage I and II NSCLC. The Cochrane Collaboration Group reviewed 11 randomised trials and concluded that 4-year survival was superior in patients undergoing any type of lung resection and complete mediastinal lymph node dissection versus sampling [57]. At present, lobectomy with systematic mediastinal lymph node dissection remains the gold standard for early-stage lung cancer. This statement has been re-emphasised recently by a panel of experts from the American College of Chest Physicians and the STS [16]. 


\section{Lobectomy versus segmentectomy}

In a landmark paper, Ginsberg and the Lung Cancer Study Group showed that lobectomy should be preferred to wedge resection or segmentectomy whenever possible, as it resulted in a much lower local recurrence rate and better cancer-free survival [58]. Recent publications suggest that this view may have to be revised in patients with small peripheral tumours and no hilar lymph node involvement. Recent evidence suggests that segmentectomy (inclusive of systematic hilar and mediastinal lymph node dissection) could be considered as a valid alternative to lobectomy in patients with tumours $<2 \mathrm{~cm}$ and limited pulmonary function $[59,60]$. Some have suggested that the ratio between surgical margin and tumour diameter should be kept $>1$ in order to minimise the risk of local relapse [61]. Recently, a large retrospective study (SEER) showed that lobectomy and segmentectomy resulted in similar survival among patients with small $(<1 \mathrm{~cm})$ tumours [62]. In a retrospective series, SIENEL et al. [63] reported that local relapse after segmentectomy was more common in the $\mathrm{S} 1-\mathrm{S} 3$ region, especially when the resection margin was $<1 \mathrm{~cm}$.

\section{The benefit of VATS lobectomy and segmentectomy}

VATS is a minimally invasive surgical approach used for both diagnostic and therapeutic lung cancer surgery (fig. 1). VATS is associated with reduced postoperative pain, reduced pulmonary dysfunction and reduced cytokines and acute-phase protein production compared to conventional (open) surgery [64]. It may also reduce duration of drainage and length of hospital stay following lung resection [65, 66]. It has been recognised for some time now that VATS lobectomy provides similar long-term results to open lobectomy in patients with stage I disease [67]. Two recent systematic reviews of the literature concluded that VATS lobectomy was associated with improved survival when compared to thoracotomy and lobectomy [65, 67]. This approach is attractive in the older population or in patients with limited pulmonary function [68, 69]. In addition, patients undergoing VATS resections appear to have fewer delays in receiving adjuvant chemotherapy and to require fewer dose reductions during adjuvant chemotherapy [70].

In patients with limited pulmonary function, thoracoscopic segmentectomy appears to have a shorter length of hospital stay, reduced morbidity and lower cost than open anatomic segmentectomy, but equivalent oncological results [71].

In 2004, Rocco [72] reported a new mini-invasive approach, the uniportal technique, involving a single anterior mini-thoracotomy together with VATs instruments and thoracoscope. Recently, GonZALES-RIVAS et al. [73] have reported excellent results with a technique using a uniportal video-assisted approach for performing lobectomy: median length of stay of 3 days, complications in $14 \%$ of patients and no 30 -day mortality.

\section{Robotic lobectomy/segmentectomy}

10 years ago, surgeons started performing lobectomies using robotic assistance [74]. This was followed by robotic anatomic segmentectomies [75]. The robotic approach involves articulated robotic arms together with a mini-thoracotomy. Large series of robotic lobectomy for early-stage lung cancer have now been reported and show excellent long-term oncological results $[15,76]$. Perioperative mortality is very low and complication rates similar to those expected with VATS lobectomy [15, 76]. PARK and Flores [77] have reported that the cost of robotic lobectomy is still more than the cost of VATS lobectomy, but less than the cost of open lobectomy. In addition, the mean operating room time for a robotic lobectomy is still $\sim 4 \mathrm{~h}$, although decreasing with experience, at most institutions [15, 76]. Considering the initial investment (robot) and the cost of disposables, this technique may be difficult to transpose to units with limited resources and set surgical volume targets. In addition, a clear benefit (postoperative pain, mortality/ morbidity or disease-free survival) over VATS lobectomy has never been proven. As a consequence only a few surgical units, mainly in the USA, have adopted robotic lobectomy as their gold standard for early-stage lung cancer.

\section{Surgery for ground-glass opacity}

Recent advances in low-dose helical CT and lung cancer screening projects have increased the detection of ground-glass opacity [78]. Bronchioloalveolar carcinoma and atypical adenomatous hyperplasia are commonly diagnosed and are sometimes multifocal, especially in patients of Asian origin [53, 54, 79]. Epidermal growth factor receptor (EGFR) and K-ras mutations have been reported frequently in patients with multifocal lesions $[80,81]$. Considering the multifocal nature of these lesions and the risk of further lesions developing subsequently, it has been suggested that sublobar resections are considered in these patients to spare lung function and allow multiple reoperations. The role of VATS lobectomy and segmentectomy, as well as single-stage bilateral surgical procedures has been emphasised in these patients $[51,52]$. In the era of effective targeted therapy, extended procedures should be used carefully, especially in patients with sensitising EGFR mutations. Those cases should be discussed in multidisciplinary meetings involving radiologists, medical and radiation oncologists. 

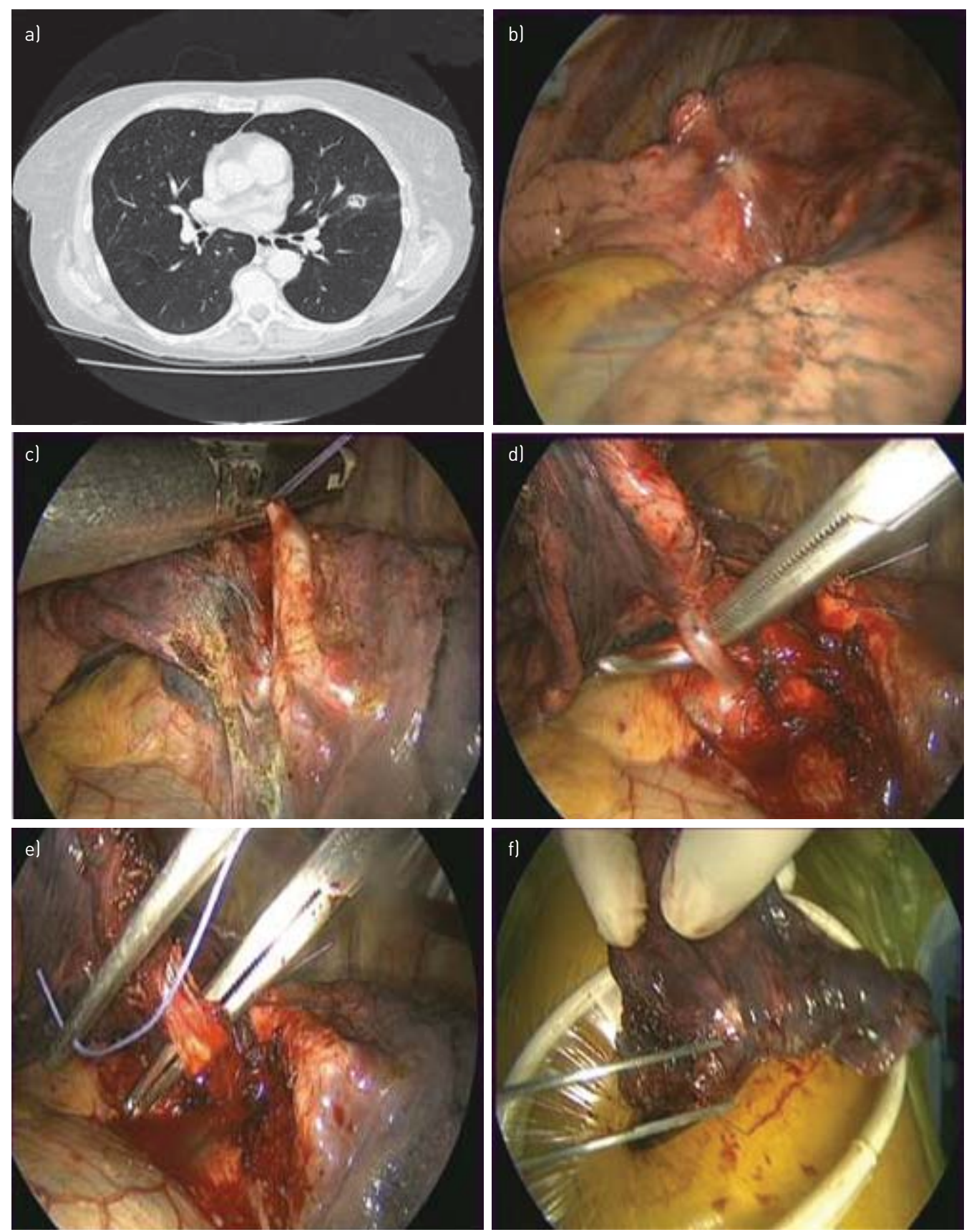

FIGURE 1 Segmentectomy performed using video-assisted thoracic surgery. a) Chest computed tomography of a 68-yearold patient showing a $13-\mathrm{mm}$ nodule in the lingula segment, near the oblique fissure. b) Videothoracoscopic view showing the nodule. Frozen sections revealed a primary lung adenocarcinoma and segmentectomy was started. The lingula segmental artery (c) and the segmental vein (d) were dissected and stapled. The segmental bronchus was divided (e) and stapled, the fissure was opened with an endolinear stapler and the segmentectomy completed. The specimen was extracted within a protective bag. Macroscopic inspection showed a surgical margin $>15 \mathrm{~mm}$ (f).

\section{Neoadjuvant chemotherapy}

The role of neoadjuvant chemotherapy in early stage lung cancer has been investigated, by DEPIERRE et al. [82] who suggested that preoperative chemotherapy appeared to act more on micrometastases than on local control. Preoperative chemotherapy may, however, delay potentially curative surgery. A systematic review and meta-analysis of seven randomised trials concluded that preoperative chemotherapy provided an absolute benefit in survival of $6 \%$ across all stages at 5 years [83]. In their meta-analysis of six studies, BERGHMANS et al. [84] showed that the hazard ratio was in favour of induction chemotherapy (hazard ratio 0.66), but suggested that more data were needed to confirm the role of such therapy. NAKAMURA et al. [85] 
reported similar findings in their meta-analysis of 564 patients assigned to surgery or preoperative chemotherapy followed by surgery. The hazard ratio was in favour of neoadjuvant chemotherapy with a significant survival difference at 1 and 3 years, but no significant difference at 5 years [85]. Both metaanalyses emphasised that the role of neoadjuvant chemotherapy was particularly marginal in patients with stage IIIA $[84,85]$. The largest trial studying neoadjuvant chemotherapy, reported to date, showed no survival advantage in patients receiving three cycles of platinum-based chemotherapy followed by surgery [86]. In this randomised trial, approximately two-thirds of patients had stage I disease, $31 \%$ had stage II disease and $7 \%$ stage IIIA disease. Postoperative complications were similar between groups and no impairment of quality of life was observed in patients receiving preoperative chemotherapy. Preoperative chemotherapy is often associated with more difficult hilar or mediastinal dissection, but this is usually manageable for a qualified thoracic surgeon. Particular attention should be given to bronchial stumps, especially after right pneumonectomy, as the risk of bronchopleural fistula seems to be higher [87]. Given the relatively small number of studies in the field, it is not recommended that patients with early-stage NSCLC receive preoperative chemotherapy routinely, outside of a trial [19].

\section{Adjuvant chemotherapy}

Many randomised controlled trials have evaluated the role of cisplatin-based adjuvant chemotherapy in NSCLC. A recent pooled analysis showed the benefit of adjuvant chemotherapy in completely resected patients. The overall survival benefit is approximately $4 \%$ at 5 years (table 3 ) [3]. The combination of vinorelbine and cisplatin offers a higher benefit compared to other doublets or triplets [3]. The analysis showed that adjuvant chemotherapy is detrimental in completely resected stage Ia NSCLC. Recently, LIM et al. [88] have reported an indirect comparison meta-analysis of 32 randomised trials involving more than 10000 patients (10 trials involving preoperative chemotherapy and 22 trials postoperative chemotherapy). They concluded that in patients with resectable lung cancer, there was no evidence of a difference in overall and disease-free survival between the timing of administration of chemotherapy (postoperative versus preoperative) [88].

\section{Surgery for stage IIIla and IIIb lung cancer N2 disease}

The role of surgery in patients with $\mathrm{N} 2$ disease remains controversial $[87,89,90]$. For many years thoracic surgeons and oncologists have been debating the role of surgery in this group of patients. A randomised controlled trial of lung resection versus radiotherapy after induction chemotherapy in patients with stage IIIA disease, published in 2007, showed no survival benefit in the surgical arm [90]. Thoracic surgeons have argued that, in this trial, the mediastinal nodal status was not reassessed routinely by mediastinoscopy and that the $\mathrm{N} 2$ group is an heterogeneous group of patients with some having a better prognosis than others. It is recognised that patients who present with bulky N2 disease at clinical staging have a different prognosis from those with microscopic N2 disease diagnosed at thoracotomy or final pathology [90]. Although patients with multiple and bulky N2 disease are certainly not ideal surgical candidates, those with single station N2 disease, especially station 5 or 6 and left upper lobe cancer and station 4R and right upper lobe cancer, represent a subgroup of patients likely to benefit from surgical resection as part of multimodality therapy [91]. Survival in this subgroup of patients approached $30 \%$ at 5 -years in some historical series [10]. It is now recognised that patients with single station N2 node have a similar survival to those with multiple N1 disease [17]. RIQUET et al. [92] have also reported that patients with skip mediastinal lymphadenopathy (N2) have a better survival than those with N1 plus N2 disease. GoldSTRAw et al. [93] showed that no extracapsular nodal invasion and squamous histology carried a better prognosis in N2 patients. Recently, it was suggested that surgery is a non-inferior treatment modality to radical chemoradiation in patients with

\section{TABLE 3 Overall survival benefit of adjuvant chemotherapy}

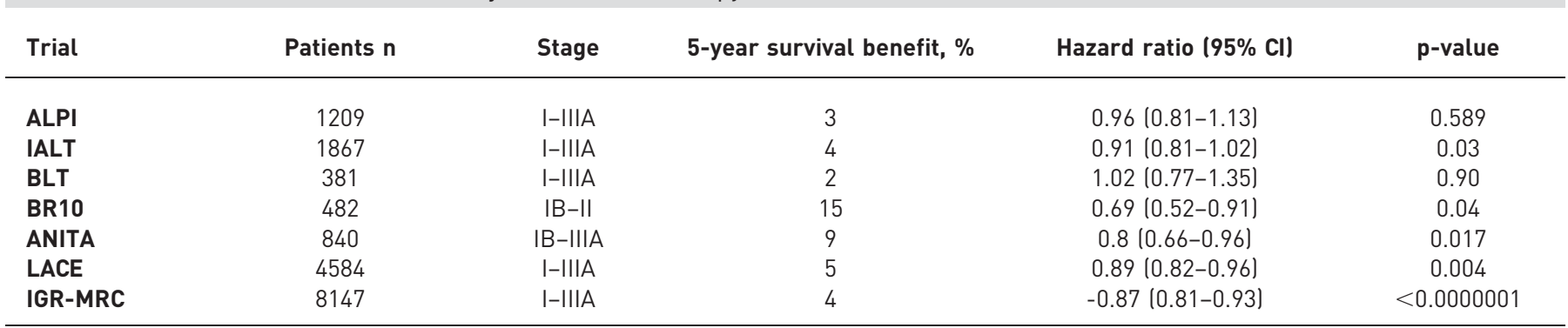

Reproduced from [3] with permission from the publisher. 
stage IIIa [19]. Based on the fact that surgery is not inferior to chemoradiation, it is suggested that patients with resectable N2 disease are offered the choice between having a lung resection or undergoing chemoradiation [19]. In all reports, the value of systematic radical mediastinal lymphadenectomy has been emphasised as it results in better 5-year survival [94].

Since the mid-1980s, there has been great interest in neoadjuvant treatment for patients with preoperatively diagnosed N2 disease [21]. In a historical series, MARTINI et al. [95] showed a response rate of $77 \%$ in patients receiving cisplatin-based chemotherapy and a complete resection rate of $65 \%$. This was followed by two randomised trials of surgery alone versus neoadjuvant chemotherapy followed by surgery in stage IIIa patients, which showed a survival benefit in those receiving preoperative chemotherapy [96, 97]. Most phase II and III studies of induction chemotherapy or chemoradiation have shown prolonged survival compared with historical series and complete pathological response (i.e. no viable tumour) in 10-20\% of patients [21, 98, 99].

The evidence is that induction chemoradiotherapy increases pathological response and mediastinal downstaging compared with only chemotherapy. However, this comes with additional complications and it is suggested that pneumonectomy, especially right sided pneumonectomy, as well as bilobectomy should be avoided after chemoradiotherapy [50, 100]. Clearly, patients undergoing lobectomy after induction chemoradiotherapy experience fewer complications and have better overall survival than those having bilobectomy or pneumonectomy. Therefore, it seems reasonable to offer surgery to patients with stage IIIa (N2) who respond well to neoadjuvant chemotherapy or chemoradiotherapy. Mediastinal lymph nodes should be reassessed following neoadjuvant treatment. EBUS and EUS seem at least as good as mediastinoscopy for that task, in experienced hands [27]. When lobectomy is the anticipated type of lung resection, chemoradiotherapy can be used with an acceptable risk of mortality and complications. When pneumonectomy is the anticipated type of lung resection, neoadjuvant chemotherapy should be preferred over chemoradiotherapy. Published evidence does not support the use of radiation therapy in induction regimens for stage IIIa (N2) [101].

Until the mid-1980s, adjuvant radiotherapy was considered a valid treatment in patients with pN2 disease [102]. However, a prospective randomised trial of the Lung Cancer Study Group showed no survival benefit in patients receiving adjuvant radiation after complete resection of stage II and stage III squamous cell carcinoma despite a clear benefit in controlling local recurrences [103]. A large meta-analysis showed that postoperative radiotherapy was detrimental and had a significant adverse effect on survival [104]. However, the detrimental effect was more pronounced in patients with stage I/II, N0-N1 disease, whereas for patients with stage III-N2 disease there was no clear evidence of an adverse effect. Recent publications suggest that postoperative radiotherapy should be discussed after completion of adjuvant chemotherapy in patients with completely resected stage IIIa-N2 NSCLC $[105,106]$. LUNG-ART, a large multi-institutional randomised trial using three-dimensional conformal radiation technique versus no radiotherapy in patients with resected stage IIIa-N2 disease is now underway [106].

Postoperative radiotherapy is recommended for patients with residual microscopic disease at the resection margin (R1) where the benefit of reduction in local recurrence outweighs the risk of mortality and morbidity related to radiotherapy [19].

The central nervous system is a common failure site after multimodality therapy of advanced stage NSCLC. Although the role of prophylactic cranial irradiation (PCI) is well established in small cell lung cancer, its role in NSCLC remains unproven [107]. Four randomised trials were performed, in the 1970s and early1980s, and most showed a reduced incidence of brain metastases with PCI, but no effect on survival, due to low power [108]. Thus, PCI cannot be recommended as standard adjuvant therapy in patients with resected stage IIIa-N2 NSCLC, as a large randomised trial would be needed.

\section{Surgery for $\mathrm{N} 3$ disease}

A recent phase II trial showed that surgery following induction chemoradiotherapy was an acceptable option in selected patients with stage IIIb disease [109]. 28\% of patients had N3 disease and 78\% had T4 disease. $48 \%$ of patients required a pneumonectomy, 30-day mortality was $5.7 \%$ and $40 \%$ suffered perioperative complications. The median overall survival was 29 months and 5 -year survival 40\%, showing that good results can be obtained in selected patients with advanced-stage disease. At present, there is no role for surgery in patients with N3 disease, outside of a clinical trial.

Chest wall resection

Chest wall invasion is present in approximately $5 \%$ of resected lung cancer patients [110]. Chest wall resection is routinely perfomed "en-bloc" with the lung specimen, with perioperative mortality rates of $1-4 \%$ [111-113]. 5-year survival rates of $40-50 \%$ have been reported in patients with stage T3N0M0 disease, but of $<20 \%$ in patients with stage IIIa disease [111-113]. Chest wall defects can be reconstructed 
or not depending upon their size and location. Various materials are routinely used to repair the chest wall: methyl metacrylate, polytetrafluoroethylene (PTFE), metallic rods and plates with excellent long-term results [110-113]. In patients whose tumour infiltrates into the parietal pleura only, en-bloc chest wall resections provide a much better survival than extrapleural resections [111]. Tumour size, number of resected ribs and $\mathrm{N}$ status influence the 5-year survival. Radiotherapy is recommended for positive chest wall margins, but its role in R0 resection is less clear [19].

\section{Diaphragmatic resection}

Invasion of the diaphragm is classified T3 in the TNM classification [114]. Few series of NSCLC with direct diaphragmatic invasion have been published [114-117]. Most series show that the depth of diaphragmatic involvement significantly affects prognosis (deep invasion being worse than superficial invasion). 5-year survival rates vary between 20 and $42 \%$. Survival is better in patients with T3N0M0 disease. Wide margins should be achieved. Direct primary repair of the diaphragm is possible in patients with limited invasion. In those with extensive involvement, complete resection and reconstruction of the diaphragm with a mesh (PTFE) is recommended. Adjuvant chemotherapy should be discussed after surgery in patients with deep diaphragmatic invasion, due to the risk of systemic progression. Soullamas et al. [118] showed that the diaphragm has an abundant lymphatic pathway draining into para-aortic nodes, anterior parasternal nodes and mediastinal nodes. Those lymph nodes centres drain into the thoracic duct, internal mammary chains and subcarinal lymph nodes, explaining the frequent association of N2 disease with diaphragmatic invasion [118]. In patients with superficial invasion (diaphragmatic pleura) and N0 disease, the role of chemotherapy is less clear, but the series are too small and there is no clear evidence in the literature. All patients diagnosed with positive lymph nodes (N1-N2) should be referred for adjuvant chemotherapy following resection.

\section{Mediastinal infiltration}

This group includes patients with T3 disease where cancer infiltrates into the mediastinal pleura, pericardium and phrenic nerve, and patients with T4 tumours where cancer infiltrates deeper into the mediastinal structures, such as great vessels (aorta, superior vena cava (SVC) and pulmonary artery), heart and oesophagus. 20 years ago, MARTINI et al. [119] showed that the extent of mediastinal invasion influenced resectability and survival. With complete resection, 5-year survival was 19\% in the absence of N2 disease. They concluded that primary surgical treatment was associated with poor survival, especially if complete resection could not be achieved [119]. More recently, a French group and a Japanese group showed that patients with pT3 mediastinal involvement had a 5 -year survival of $30-40 \%$ in the setting of multimodality therapy $[115,120]$. Factors for poor outcomes were N2 disease and incomplete resection. The type of resection (pneumonectomy versus lobectomy) did not seem to influence survival significantly [115].

\section{Superior sulcus tumours (Pancoast tumours)}

Due to its localisation in the lung apex with invasion of the first ribs, lower brachial plexus and sometimes vertebrae and subclavian vessels, these tumours represent a relative therapeutic challenge (fig. 2) [121]. These tumours are classified T3 or T4 depending on the surrounding structures involved. Before 1950, these tumours were uniformly fatal. Shaw and Paulson introduced multimodality therapy, combining radiotherapy and a posterior approach to the tumour, providing a 5-year survival of 30\% [121]. Subsequently, Dartevelle et al. [122] and then GrunENWALD and SPAGGiari [123] introduced the transcervical approach and the transmanubrial approaches, allowing resection of tumours invading the subclavian vessels. En-bloc resection of the upper lobe, ribs, nerves (brachial plexus) plus or minus vessels is recommended. Many studies published in the past 10 years have established the gold standard in the field as induction therapy consisting of high dose radiotherapy with concurrent cisplatin-based chemotherapy, followed by surgery 4-6 weeks later [124-129]. Using this multimodality scheme, perioperative mortality is low and 5-year survival rates are now consistently $>40 \%$. Recent studies have shown that complete response to induction therapy was a significant predictive factor for overall survival [124-126]. Late central nervous system relapse remains a problem and the role of PCI should be evaluated in this group of patients [129].

\section{Carinal resections and sleeve pneumonectomies}

Carinal invasion is classified T4 in the TNM classification (fig. 3). Resection of lung cancer involving the carina remains a challenge because of specific technical problems and airway management [130]. The intraoperative airway management consists of high-frequency jet ventilation or intermittent conventional ventilation through the operative field. Rarely, cardiopulmonary bypass is required [131]. Isolated tracheobronchial resections can be performed without lung resections, but in many cases a lobectomy or a pneumonectomy is necessary $[130,132-134]$. Perioperative mortality remains high: $2.5 \%$ to $15 \%$ in most series. Complications mostly include pneumonia, adult respiratory distress syndrome (following pneumonectoy) and anastomotic complications (leakage or stenosis) [130, 132-134]. Nodal status has a 

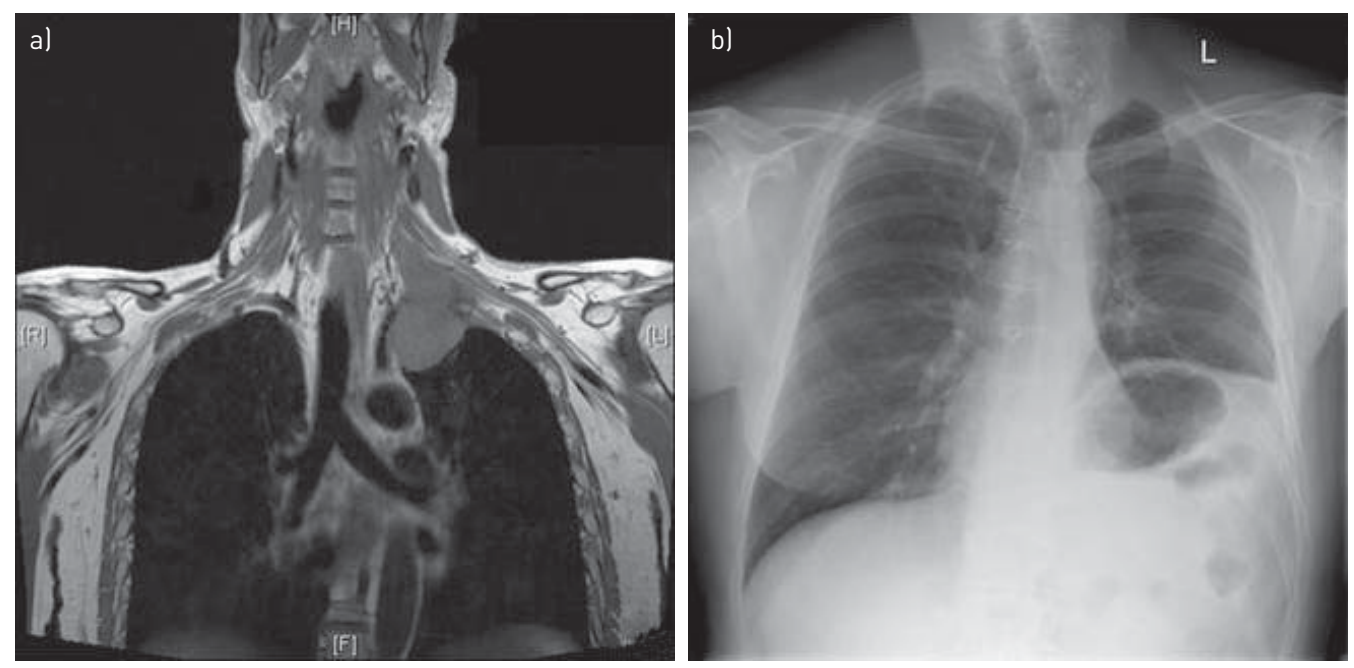

FIGURE 2 A left pancoast tumour. a) Chest magnetic resonance imaging of a left pancoast tumour arising in the left upper lobe and infiltrating the first rib, brachial plexus and left subclavian artery. The patient received induction chemoradiotherapy: three cycles of vinorelbin and cisplatin, as well as $45 \mathrm{~Gy}$. He underwent en bloc resection through sternotomy and supraclavicular approach, the left upper lobe and the three first ribs were removed and the left subclavian artery was reconstructed. The left phrenic and vagus nerves had to be sacrificed. Histopathology showed a primary lung adenocarcinoma with $>90 \%$ necrosis. b) Chest radiography of the same patient 4 years post-operatively. There is obvious left phrenic nerve palsy. The patient had a positron emission tomography-computed tomography scan at 5 years which showed no sign of relapse.

significant impact on survival, with 5-year survival rates up to $51 \%$ in patients with N0 disease and down to $0-12 \%$ in those with $\mathrm{N} 2$ disease $[130,132-134]$. Therefore, surgery is recommended for patients with $\mathrm{N} 0-\mathrm{N} 1$ disease, as the benefit is worth the risk, but most surgeons now do not recommend carinal resection when N2 disease is proven preoperatively. Although induction chemotherapy may represent an acceptable treatment, performing a carinal resection following induction chemoradiotherapy carries a very high risk of anastomotic complications, fistula and death, and is, therefore, not advisable.

\section{Resection of great vessels and heart}

A few surgical series have reported on patients with lung cancer and invasion of the heart or great vessels. Although lung cancer with direct invasion into the epicardium or myocardium is considered inoperable by most surgeons, cancer invading the left atrium, aorta, or proximal pulmonary artery can be resected with or without cardiopulmonary bypass [135]. Extracorporeal circulation is well known to cause lung injury and most surgeons use it reluctantly, especially when pneumonectomy is anticipated [136]. In a recent systematic review of the literature MURALIDARAN et al. [135] showed that overall survival at 5-years was 37\% in patients undergoing lung cancer resection on circulatory bypass. Survival was significantly higher when placement on bypass was planned preoperatively [135]. Most series have shown that 30-day mortality was acceptable, even when cardiopulmonary bypass was used [137]. In patients with a tumour infiltrating the origin of the pulmonary vein, a large clamp can be placed on the left atrium and the origin of the vein excised with a cuff of normal atrium. Direct repair or patch repair can be achieved with low mortality and good mid-term results [138]. However, this approach carries a risk of incomplete resection as microscopic invasion is difficult to assess intraoperatively [139]. In addition, this technique can result in a small left atrium with low cardiac output syndrome. The use of cardiopulmonary bypass allows for a better exploration of the atrium and for a technically easier patch reconstruction if necessary. A large margin can be taken to avoid incomplete resection. This technique is preferable in patients with significant invasion of the left atrial wall.

The SVC and subclavian arteries have been resected for some time now, without cardiopulmonary bypass, with acceptable perioperative mortality and good long-term outcomes [140-144]. SVC reconstruction can be achieved by direct repair or patch (pericardium) in patients with localised infiltration. In most patients, graft interposition is necessary (PTFE). Long-term graft patency is excellent, but anticoagulation is recommended for at least 12 months postoperatively, to avoid graft occlusion and SVC syndrome [142, 143]. Perioperative mortality rates of $5-14 \%$ have been reported [140, 143]. Recently, induction therapy has been used in most centres for cancers infiltrating the SVC. Residual N2 disease diagnosed after induction therapy has been regarded as a contraindication to the performance of lung and SVC resection due to the poor long-term survival [141]. 5-year overall survival in patients undergoing lung resection en-bloc with SVC is $>30 \%$, it is worse in patients with N2 disease versus N0-N1 (52\% versus $21 \%$ in a recent series) $[140,141,143]$. 

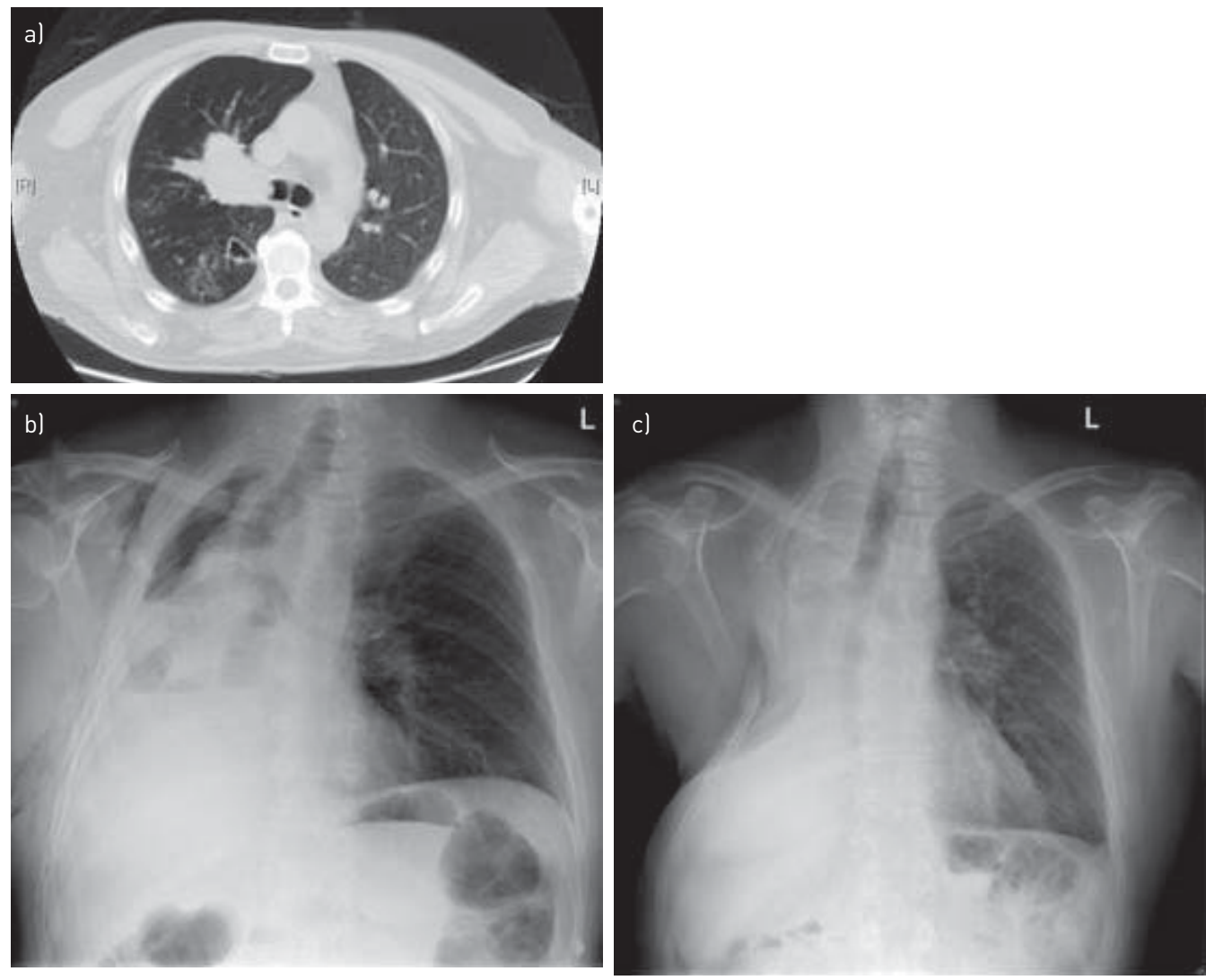

FIGURE 3 Right sleeve pneumonectomy for T4 squamous cell carcinoma. a) Chest computed tomography (CT) showing squamous cell carcinoma infiltrating the right main bronchus and carina, with marked obstructive changes and bronchiectasis in the right lower lobe. The right pulmonary artery was infiltrated as well. Cervical mediastinoscopy was performed and showed no invasion of lymph node stations 2R, 4R, 3 and 7. Positron emission tomography-CT showed no distant metastases. The patient was offered extended right pneumonectomy. He developed bronchopleural fistula and had an open pleural window 6 weeks post-operatively. b). He underwent reconstructive thoracoplasty at 2 years and remains disease-free at 4 years, with secondary pulmonary hypertension (c).

Subclavian arteries are most often involved by tumours infiltrating the thoracic inlet [145]. En-bloc resection of the subclavian artery and upper lobe is usually possible without the use of cardiopulmonary bypass (unless the origin of the artery is involved on the aortic arch) [146]. Direct end-to-end anastomosis is possible, but carries an increased risk of stenosis. Graft interposition is used at most centres (ringed PTFE graft) with excellent long-term patency. FADEL et al. [145] reported no perioperative mortality, no stroke or limb ischaemia in a recent series of 34 consecutive patients. The overall 5 -year survival was $36 \%$.

\section{Vertebral resections}

Several groups have now reported en-bloc resections of lung cancer and vertebrae. Spinal invasion is classified T4 in the TNM classification. Interventions involve either hemi-vertebrectomies or total vertebrectomies and are performed with the assistance of spinal surgeons or neurosurgeons [147-150]. A separate approach is usually necessary for spinal fixation. Perioperative mortality is nil in most series [147-149], but $8.7 \%$ in the Toronto group series [150]. Complete resection can be achieved in the vast majority of patients (80-91\%). The initial report by GRUNENWALD et al. [147] stated a 5-year survival of $14 \%$, but more recent experiences involving induction chemo- and radiotherapy report 5-year survival rates of $31-47 \%$ [147-149].

\section{Ipsilateral pulmonary nodules}

In the seventh edition of the TNM classification, patients with intrapulmonary nodule(s) (satellite lesion) are classified T3 for nodule(s) in the same lobe, T4 for nodule(s) in a different lobe, but ipsilateral lung as the main lung cancer. The respective 5-year survival rates of these patients are $28 \%$ and $22 \%$ [151]. Previous reports had shown that surgery in those patients was associated with prolonged survival, especially in nodenegative (N0) patients [152-155]. Consequently, patients with cT3N0 or cT4N0 disease should be offered surgery upfront if complete resection is achievable. As main tumour size, histology and nodal status are 
important prognostic variables associated with outcome, consideration should be given to multimodality therapy in patients with positive nodes or aggressive tumour biology.

\section{Surgery for stage IV lung cancer (solitary metastasis)}

For many years, surgeons have offered curative resections to patients presenting with a solitary synchronous brain or adrenal metastasis $[156,157]$. Resection of the metastatic lesion is offered when the primary site is controlled. Although the prognosis of brain metastasis is poor, with a median survival of $<1$ year, options are available for fit patients with lung cancer and solitary brain metastasis [158].

Whole-brain radiation therapy is widely used in patients with brain metastases. Whole-brain radiation therapy can also be used as adjuvant therapy following surgery or stereotactic radiosurgery [158]. Surgery provides a rapid relief of mass effect and is considered the treatment of choice for a large solitary metastasis. Stereotactic radiosurgery confers local control rates comparable to those obtained with neurosurgery, with minimal toxicity and versatility that makes it applicable to deep seated lesions and to patients unfit for neurosurgical resection. Treatment of the brain metastasis is usually undertaken first. Reported 5-year survival rates are 11-21.4\%. Univariate analyses usually show a better prognosis for patients with adenocarcinoma, small pulmonary tumours and N0 disease $[159,160]$.

Solitary adrenal metastases have been commonly reported in lung cancer patients. Adrenal metastases can be resected in a separate anaesthetic session, through an open or laparoscopic approach [161-164]. I have described a transdiaphragmatic approach allowing simultaneous resection of the lung cancer primary and of the homolateral adrenal metastasis through thoracotomy [165]. In a recent retrospective study from centres in the USA, RAZ et al. [161] reported a 5-year survival of $34 \%$ following excision of solitary adrenal metastasis. Patients with a synchronous metastasis usually have a shorter survival than those presenting with metachronous metastasis $[166,167]$. However, a durable long-term survival is achievable in both groups of patients ( $\sim 25 \%$ at 5 -years) [166].

Excision of metastases at other sites is rarely performed. A recent systematic review of the literature identified 62 cases having had bone, hepatic, gastrointestinal, thyroid and other metastatic sites resected with a 5-year survival rate of 50\% [168]. Although this aggressive approach is used in exceptional cases, it should not be forgotten, especially in young patients and those who are fit to undergo multisite resections. In the same way, it does not seem illogical to offer resection of a persistent metastatic site, when disease at other sites has been controlled for some time by systemic therapy or targeted therapy.

Malignant pleural disease, malignant pleural effusion and/or pleural nodules, is classified M1a in the seventh edition of the TNM classification and the associated 5-year survival is reported to be poor. However, recent publications have reported 5-year survival rates of $16-63.6 \%$ in patients with malignant pleural disease discovered at thoracotomy $[169,170]$. Five-year survival seems to be better in patients with N0-N1 disease, in those with pleural nodules and those undergoing lobectomy [169, 170]. Long-term survival is very poor in patients with $\mathrm{N} 2$ disease. Therefore, patients discovered with malignant pleural disease at thoracotomy, in whom N2 disease has not been diagnosed during staging investigations, may still benefit from complete excision of the lung primary tumour and associated pleural disease. A prospective randomised trial evaluating the role of surgery and chemotherapy versus chemotherapy alone in this subgroup of patients may help clarify the situation.

\section{Reoperations for cancer and completion pneumonectomy}

Reoperations are not exceptional in lung cancer patients [171]. Patients can present with a second primary lung cancer, a local recurrence, a metastasis or be considered early for reoperation if pathology shows incomplete resection [172]. Depending upon the disease-free interval, performance status, comorbidities, residual pulmonary function and location of the cancer, the entire range of lung resections can be considered for reoperation. Reoperative surgery is notoriously more difficult due to adhesions and disrupted anatomy. Perioperative blood loss is usually more significant than during first-time surgery. In three recent series, the perioperative mortality of completion pneumonectomy was $10-16 \%$ at large teaching institutions and postoperative complications occurred in $41-55 \%$ of patients [173-175]. Nonetheless, redo surgery can be justified by the good long-term results of completion pneumonectomy: $37-46 \%$ survival at 5-years [173-175].

\section{Surgery in the elderly}

Life expectancy has increased regularly in the western world since the Second World War. Today, it is not uncommon to see "active" octogenarians in our clinic referred for consideration of lung resection. Comorbidities, such as diabetes, renal failure, ischaemic heart disease, congestive heart failure, stroke and peripheral vascular disease, are more common in this population. Many publications have shown that the 
perioperative mortality of lobectomy or segmentectomy in a patient over 80 years-old is not higher than in the normal population of lung cancer patients [176-178]. Although survival and quality of life are good following lobectomy or segmentectomy, pneumonectomy carries a poor survival ( $\sim 10 \%$ at 5 years) [176]. 5 -year survival is influenced by the TNM stage, as expected in the general population. Dyspnoea at presentation seems to be a factor for poor prognosis in the elderly population [176]. Long and haemorrhagic procedures should be avoided and it is important to remember that a relatively minor complication can rapidly transform into a catastrophe in an elderly patient. Pulmonary arteries and branches are more fragile in the elderly and can rupture during manipulations or retraction. The bronchi are generally more calcified. Therefore, particular attention should be paid and suturing and stapling should be particularly meticulous in elderly patients. Personally, I set a very low threshold for sending these patients, prophylactically, to a high-dependency unit for $24 \mathrm{~h}$ postoperatively and being particularly proactive in monitoring them (continuous monitoring of heart rate, invasive blood pressure monitoring and continuous arterial oxygen saturation monitoring, noninvasive ventilation and precise measurement of urine output with a urine catheter). The patient should be ambulated early and adequate pain control should be ensured. Altogether, if the lung cancer can be resected by any resection that is less than a pneumonectomy, the risk/benefit ratio seems to favour surgery. For those requiring pneumonectomy, the risk seems particularly high and one should discuss alternative therapies such as radiotherapy plus or minus systemic therapy. The role of video-assisted surgery and minimally-invasive procedures in the elderly population has been emphasised by several groups. VATS lobectomy in the elderly is associated with fewer and an overall reduced severity of complications, as well as a shorter hospital stay compared to thoracotomy $[69,179]$.

\section{Lung resections in HIV-positive patients}

There is limited literature regarding the treatment and outcome of lung cancer treatment in HIV-infected patients. The risk of developing lung cancer seems to be higher in the HIV-positive population as most patients are smokers and many have a history of drug abuse [180]. Lung cancer is typically diagnosed a decade earlier (mean age 45 years) in the HIV-infected population and most of the time patients have advanced-stage disease. Several publications in the 1990s reported unfavourable outcomes in the HIVpositive population [181, 182]. In the era of highly active antiretroviral therapy, it seems that survival following lung resection should be comparable to that of patients without HIV infection, although this has been questioned recently $[181,183]$. It is recognised that patients with CD4 count $>200 \mathrm{cells} \cdot \mathrm{uL}^{-1} \mathrm{can}$ receive chemotherapy safely. Therefore, HIV-positive status should not be a contraindication to surgery in patients whose fitness and immune status qualify them for a lung resection. Postoperative pulmonary infections seem to be more common and atypical mycobacteria are more commonly found in the surgical specimens of HIV-infected patients. Therefore, antibiotic and antifungal therapies should be discussed with the local microbiology team preoperatively on an individual basis and immune status should be optimised before surgery. Prophylactic cover of the bronchial stump should be considered in patients with known mycobacterial infection to reduce the risk of bronchopleural fistula [184].

\section{Surgery in patients with impaired pulmonary function}

Preoperative optimisation including smoking cessation, improved nutrition, use of inhalers or bronchodilators, steroids, pulmonary rehabilitation is recommendable in patients with chronic obstructive pulmonary disease $[185,186]$.

Prophylactic admission to a high-dependency unit is recommended for patients with a predicted postoperative FEV1 of 44\%. Patients with fibrotic lung disease or severe interstitial lung disease should also be admitted prophylactically to a high-dependency unit [187]. Patients with an American Society of Anesthesiologists (ASA) physical status classification system score $\geqslant 3$, or poor performance status should also be admitted to a high-dependency unit. Protective (low-tidal volume) ventilatory strategies should be applied during one-lung ventilation and close monitoring is recommended for 5 days in patients following extensive lymphatic dissection [187].

Experience from lung volume reduction surgery has shown that some patients who would have been considered inoperable can safely undergo lung cancer resection [188]. Therefore, lung resection should be considered even in patients with very poor pulmonary function, when the tumour is situated in the most emphysematous lobe [19]. Recently, an analysis of the STS database showed that thoracotomy had a markedly negative impact on complications compared with VATS lobectomy in patients with FEV1 $<60 \%$ predicted or DLCO $<60 \%$ predicted [31].

\section{Impact of surgical volume and surgeon's specialty on outcomes in lung cancer} surgery

Multiple publications have shown that the volume of lung cancer resections performed at a hospital was positively associated with the survival of patients [189]. Patients operated on at high-volume hospitals have 
lower postoperative complication rates and lower 30-day mortality [189]. Outcomes seem to be better in large teaching hospitals $[190,191]$ and the surgeon's specialisation, thoracic surgery versus general surgery or cardiothoracic surgery, also influences in-hospital mortality [192, 193].

\section{Palliative surgery}

\section{Lung resections}

Some patients present with advanced-stage lung cancer (metastatic or locally-advanced) and would under normal circumstances not be considered for surgery. However, some circumstances may warrant a lung resection, i.e. massive haemoptysis (not settling with radiotherapy or percutaneous embolisation). In the same register, a large cavitated or infected tumour may preclude the safe administration of palliative chemotherapy due to the risk of sepsis or tumour perforation.

In routine practice, it is not exceptional to be referred patients who have perforated a large tumour on chemotherapy or chemoradiotherapy. This is a catastrophic situation where the patient has a bronchopleural fistula and a pleural empyema. Neither chemotherapy nor radiotherapy can be offered until the empyema has resolved. When the patient has a life expectancy of $>3$ months it seems justified to offer a surgical intervention to drain the empyema and close the bronchopleural fistula using an adequate method that may involve a lung resection, such as a wedge resection, segmentectomy or lobectomy. Extensive procedures are to be avoided in these patients and atypical therapeutic plans should ideally be approved in a multidisciplinary meeting and should be documented in the patient's notes. For those with a performance status $>3$ or a short life expectancy, insertion of a chest drain and supportive care represent an acceptable option.

\section{Malignant pleural effusion and malignant pericardial effusion}

Malignant pleural effusion is staged M1 in the new TNM classification. This is a very common problem in thoracic surgical practice. Sometimes, the pleural effusion will reveal the cancer through dyspnoea and cough. In other cases, the pleural effusion will accumulate during follow-up, after a diagnosis of lung cancer has been established. In patients fit for a surgical procedure, a videothoracoscopy, usually performed under general anaesthesia, or a medical thoracoscopy, usually performed under i.v. sedation and local anaesthesia, can be offered to drain the effusion and obtain multiple pleural biopsies for histopathology and mutational analysis. The available evidence supports the need for chemical sclerosants for successful pleurodesis; using talc as the sclerosant of choice ( $5 \mathrm{~g}$ of sterile talc) and thoracoscopic pleurodesis as the preferred technique for pleurodesis, based on efficacy. There is no evidence for an increase in mortality following talc pleurodesis [194, 195]. In a large series of 611 patients, CARDILlo et al. [196] showed that perioperative mortality was less than $1 \%$ and morbidity $3 \%$. A histological diagnosis was obtained in all patients and after a median follow-up of 64 months talc pleurodesis was successful in $92.7 \%$ of patients [196].

Talc should not be insufflated in the pleural cavity if the lung does not re-expand following drainage of the effusion ("trapped lung") as this substantially increases the risk of empyema. In those patients with trapped lung, a tunnelled pleural catheter should be placed. In a recent series, HuNT et al. [197] showed that tunnelled pleural catheter placement was associated with a reduced length of hospital stay and fewer reinterventions compared with VATS talc pleurodesis.

Malignant pericardial effusion is staged M1 in the new TNM classification. Malignant pericardial effusion can rapidly become life-threatening and a large proportion of patients present with acute tamponade. The management is relatively straightforward and depends mainly on the patient's haemodynamic status and whether or not a diagnosis of lung cancer is established. Patients with haemodynamic instability should have percutaneous balloon catheter drainage under ultrasound control and pericardial fluid should be sent for cytology [198]. Two recent trials in patients with lung cancer reported that the median survival after percutaneous pericardial drainage was between 2 and 4.5 months [199, 200]. For patients in whom a diagnosis of lung cancer is established, it is perfectly acceptable to offer pericardial sclerosis with intrapericardial bleomycin. This procedure is safe and highly successful [199, 200]. When a diagnosis is lacking and the patient is haemodynamically stable, pericardial tissue can be obtained by performing a pericardial window either using the subxyphoid approach or a videothoracoscopic approach [201, 202]. Recurrence of pericardial effusion seems to be more common after the subxyphoid approach [201], but this procedure can be performed under sedation and local anaesthesia in compromised patients. VATS requires a double-lumen tube and single-lung ventilation, but provides excellent exposure to the pericardium. Moreover, a significant pleural effusion can be drained at the same time [202]. The access side should be the one of the lung cancer or the side of the larger pleural effusion. Both the subxyphoid window and the videothoracoscopic window allow performance of large pericardial biopsies for histopathology and mutational analyses. 


\section{Interventional bronchology, laser, cryotherapy and stenting}

Although the thoracic surgeon may not be directly involved in the care of terminally-ill lung cancer patients, an opinion is sometimes requested in patients with central airway obstruction, tracheo-oesophageal fistula, severe haemoptysis, or superior vena cava syndrome [203]. The care of these patients is often shared with interventional radiologists, pulmonologists and oncologists. Tracheal and main bronchial obstructions are treated by bronchoscopic interventions (laser debulking, cryotherapy, airway stenting, photodynamic therapy, endobronchial brachytherapy) [204, 205]. Palliative radiotherapy is often used subsequently [204, 205]. Tracheo-oesophageal fistulas are best palliated by insertion of a covered stent in the oesophagus and a stent in the airway to prevent secondary collapse of the airway [206]. Lastly, endovascular stenting provides rapid relief of symptoms in superior vena cava syndrome with minimal morbidity and complications [207].

\section{Conclusion}

Survival following lung cancer resection remains poor, except in patients with early-stage disease where cancer can be cured in more than $60-70 \%$ of cases. Nonetheless, surgery remains the best chance of cure for lung cancer patients and an invaluable palliative treatment modality in many. As surgical techniques are unlikely to change dramatically in the next decade, our efforts should concentrate on early diagnosis, better understanding of tumour biology, development of biomarkers and effective systemic and targeted therapies.

\section{References}

Malvezzi M, Bertuccio F, Levi F, et al. European cancer mortality predictions for the year 2013. Ann Oncol 2013; 24: 792-800.

2 Ferlay J, Steliarova-Foucher E, Lortet-Tieulent J, et al. Cancer incidence and mortality patterns in Europe: estimates for 40 countries in 2012. Eur J Cancer 2013; 49: 1374-1403.

3 Le Chevalier T. Adjuvant chemotherapy for resectable non-small cell lung cancer: where is it going? Ann Oncol 2010; 21: Suppl. 7, vii196-vii198.

4 Wright G, Manser RL, Byrnes G, et al. Surgery for non-small cell lung cancer: systematic review and meta-analysis of randomised controlled trials. Thorax 2006; 61: 597-603.

5 Howington JA, Blum MG, Chang AC, et al. Treatment of stage I and II non-small cell lung cancer: diagnosis and management of lung cancer, 3rd ed: American College of Chest Physicians evidence-based clinical practice guidelines. Chest 2013; 143: Suppl. 5, 278S-313S.

6 Evarts A, Graham MD, Singer JJ. Successful removal of an entire lung for carcinoma of the bronchus. JAMA 1984; 251: $257-260$.

7 Jensik RL, Faber LP, Milloy FJ, et al. Segmental resection for lung cancer. A 15-year experience. J Thorac Cardiovasc Surg 1973; 66: 563-572.

8 Thomas CP. The present position relating to cancer of the lung. Lobectomy with sleeve resection. Thorax 1960; 15: 9-11.

9 Locicero J III, Ponn RB, Daly BDT. Surgical treatment of non-small cell lung cancer. In: Shields TW, LoCicero J, Ponn RB, et al., eds. General Thoracic Surgery. 5th Edn. Lipincott Williams and Wilkins, Philadelphia, USA, 2000; pp. 1311-1341.

10 Martini N, Flehinger BJ, Zaman MB, et al. Results of resection in non-oat cell carcinoma of the lung with mediastinal lymph node metastases. Ann Surg 1983; 198: 386-397.

11 Lewis RJ, Caccavale RJ, Sisler GE, et al. Video-assisted thoracic surgical resection of malignant lung tumors. J Thorac Cardiovasc Surg 1992; 104: 1679-1685.

12 Walker WS, Carnochan FM, Pugh GC. Thoracoscopic pulmonary lobectomy. Early operative experience and preliminary clinical results. J Thorac Cardiovasc Surg 1993; 106: 1111-1117.

13 McKenna RJ Jr. Lobectomy by video-assisted thoracic surgery with mediastinal node sampling for lung cancer. J Thorac Cardiovasc Surg 1994; 107: 879-881.

14 Grills IS, Hope AJ, Guckenberger M, et al. A collaborative analysis of stereotactic lung radiotherapy outcomes for early-stage non-small cell lung cancer using daily online cone-beam computed tomography image-guided radiotherapy. J Thorac Oncol 2012; 7: 1382-1393.

15 Park BJ, Melfi F, Mussi A, et al. Robotic lobectomy for non-small cell lung cancer (NSCLC): long-term oncologic results. J Thorac Cardiovasc Surg 2012; 143: 383-389.

16 Donington J, Ferguson M, Mazzone P, et al. American College of Chest Physicians and Society of Thoracic Surgeons consensus statement for evaluation and management for high-risk patients with stage I non-small cell lung cancer. Chest 2012; 142: 1620-1635.

17 Rusch VW, Crowley J, Giroux DJ, et al. The IASLC lung cancer staging project: proposals for the revision of the N descriptors in the forthcoming seventh edition of the TNM classification for lung cancer. J Thorac Oncol 2007; 2: 603-612.

18 Goldstraw P, Crowley J, Chansky K, et al. The IASLC lung cancer staging project: proposals for the revision of the TNM stage groupings in the forthcoming (seventh) edition of the TNM classification of malignant tumours. $J$ Thorac Oncol 2007; 2: 706-714.

19 Lim E, Baldwin D, Beckles M, et al. Guidelines on the radical management of patients with lung cancer. Thorax 2010; 65: Suppl. 3, iiil-iii27.

20 Deslauriers J. Current surgical treatment of nonsmall cell lung cancer 2001. Eur Respir J 2002; 19: Suppl. 35, 61s-70s.

21 Berghmans T, Dusart M, Paesmans M, et al. Primary tumor standardized uptake value (SUVmax) measured on fluorodeoxyglucose positron emission tomography (FDG-PET) is of prognostic value for survival in non-small cell lung cancer (NSCLC): a systematic review and meta-analysis (MA) by the European Lung Cancer Working Party for the IASLC Lung Cancer Staging Project. J Thorac Oncol 2008; 3: 6-12. 
22 Bowen TE, Zajtchuk R, Green DC, et al. Value of anterior mediastinotomy in bronchogenic carcinoma of the left upper lobe. J Thorac Cardiovasc Surg 1978; 76: 269-271.

23 Ginsberg RJ, Rice TW, Goldberg M, et al. Extended cervical mediastinoscopy. A single staging procedure for bronchogenic carcinoma of the left upper lobe. J Thorac Cardiovasc Surg 1987; 94: 673-678.

24 De Leyn P, Lardinois D, Van Schil PE, et al. ESTS guidelines for preoperative lymph node staging for non-small cell lung cancer. Eur J Cardiothorac Surg 2007; 32: 1-8.

25 Medford AR, Bennett JA, Free CM, et al. Medistinal staging procedures in lung cancer: EBUS, TBNA and mediastinoscopy. Curr Opin Pulm Med 2009; 15: 334-342.

26 Lee BE, Redwine J, Foster C, et al. Mediastinoscopy might not be necessary in patients with non-small cell lung cancer with mediastinal lymph nodes having a maximum standardized uptake value of less than 5.3. J Thorac Cardiovasc Surg 2008; 135: 615-619.

27 Yasufuku K, Pierre A, Darling G, et al. A prospective controlled trial of endobronchial ultrasound-guided transbronchial needle aspiration compared with mediastinoscopy for mediastinal lymph node staging of lung cancer. J Thorac Cardiovasc Surg 2011; 142: 1393-1400.

28 Yokoi K, Kamiya N, Matsuguma H, et al. Detection of brain metastasis in potentially operable non-small cell lung cancer: a comparison of CT and MRI. Chest 1999; 115: 714-719.

29 Blake MA, Slattery JM, Kalra MK, et al. Adrenal lesions: characterization with fused PET-CT image in patients with proved or suspected malignancy - initial experience. Radiology 2006; 238: 970-977.

30 Hsia TC, Shen YY, Yen RF, et al. Comparing whole-body ${ }^{18} \mathrm{~F}$-2-deoxyglucose positron emission tomography and technetium-99m methylene diophosphate bone scan to detect bone metastases in patients with non-small cell lung cancer. Neoplasma 2002; 49: 267-271.

31 Ceppa DP, Kosinski AS, Berry MF, et al. Thoracoscopic lobectomy has increasing benefit in patients with poor pulmonary function: a Society of Thoracic Surgeons Database analysis. Ann Surg 2012; 256: 487-493.

32 Treasure T, Utley M, Bailey A. Assessment of whether in-hospital mortality for lobectomy is a useful standard for the quality of lung cancer surgery: retrospective study. BMJ 2003; 327: 73.

33 Shapiro M, Swanson SJ, Wright CD, et al. Predictors of major morbidity and mortality after pneumonectomy utilizing the Society for Thoracic Surgeons General Thoracic Surgery Database. Ann Thorac Surg 2010; 90: 927-934.

34 Berrisford R, Brunelli A, Rocco G, et al. The European Thoracic Surgery Database project: modelling the risk of inhospital death following lung resection. Eur J Cardiothorac Surg 2005; 28: 306-311.

35 Harpole DH Jr, DeCamp MM Jr, Daley J, et al. Prognostic models of thirty-day mortality and morbidity after major pulmonary resection. J Thorac Cardiovasc Surg 1999; 117: 969-979.

36 Falcoz PE, Conti M, Brouchet L, et al. The thoracic surgery scoring system (THORACOSCORE): risk model for inhospital death in 15,183 patients requiring thoracic surgery. J Thorac Cardiovasc Surg 2007; 133: 325-332.

37 Kozower BD, Sheng S, O’Brien SM, et al. STS database risk models: predictors of mortality and major morbidity for lung cancer resction. Ann Thorac Surg 2010; 90: 875-881.

38 Fleisher LA, Beckman JA, Brown KA, et al. ACC/AHA 2007 guidelines on perioperative cardiovascular evaluation and care for non-cardiac surgery: a report of the American College of cardiology/American Heart Association task force on practice guidelines. J Am Coll Cardiol 2007; 50: e159-e242.

39 Armstrong P, Congleton J, Fountain SW, et al. BTS guidelines: guidelines on the selection of patients with lung cancer for surgery. Thorax 2001; 56: 89-108.

40 Ferguson MK, Vigneswaran WT. Diffusing capacity predicts morbidity after lung resection in patients without obstructive lung disease. Ann Thorac Surg 2008; 85: 1158-1164.

41 Beckles MA, Spiro SG, Colice GL, et al. The physiologic evaluation of patients with lung cancer being considered for resectional surgery. Chest 2003; 123: Suppl. 1, 105S-114S.

42 Ohno Y, Koyama H, Nogami M, et al. Postoperative lung function in lung cancer patients: comparative analysis of predictive capability of MRI, CT and SPECT. AJR Am J Roentgenol 2007; 189: 400-408.

43 Darling GE, Abdurahman A, Yi QL, et al. Risk of a right pneumonectomy: role of bronchopleural fistula. Ann Thorac Surg 2005; 79: 433-437.

44 Schirren J, Eberlein M, Fischer A, et al. The role of sleeve resections in advanced nodal disease. Eur J Cardiothorac Surg 2011; 40: 1157-1163.

45 Schirren J, Bölükbas S, Bergmann T, et al. Prospective study on perioperative risks and functional results in bronchial and bronchovascular sleeve resections. Thorac Cardiovasc Surg 2009; 57: 35-41.

46 Tronc F, Grégoire J, Rouleau J, et al. Long-term results of sleeve lobectomy for lung cancer. Eur J Cardiothorac Surg 2000; 17: 550-556.

47 Yildizeli B, Fadel E, Mussot S, et al. Morbidity, mortality and long-term survival after sleeve lobectomy for nonsmall cell lung cancer. Eur J Cardiothorac Surg 2007; 31: 95-102.

48 Galetta D, Solli P, Borri A, et al. Bilobectomy for lung cancer: analysis of indications, postoperative results and long-term outcomes. Ann Thorac Surg 2012; 93: 251-257.

49 Icard P, Heyndrickx M, Galateau-Sallé F, et al. Does bilobectomy offer satisfactory long-term survival outcome for non-small cell lung cancer? Ann Thorac Surg 2013; 95: 1726-1733.

50 Choh JH, Kim J, Kim K, et al. Risk associated with bilobectomy after neoadjuvant concurrent chemoradiotherapy for stage IIIA-N2 non-small cell lung cancer. World J Surg 2012; 36: 1199-1205.

51 Mun M, Kohno T. Efficacy of thoracoscopic resection for multifocal bronchioloalveolar carcinoma showing pure ground-glass opacities of $20 \mathrm{~mm}$ or less in diameter. J Thorac Cardiovasc Surg 2007; 134: 877-882.

52 Nakata M, Sawada S, Yamashita M, et al. Surgical treatments for multiple primary adenocarcinoma of the lung. Ann Thorac Surg 2004; 78: 1194-1199.

53 Lim E, Clough R, Goldstraw P, et al. Impact of positive pleural lavage cytology on survival in patients having lung resection for non-small cell lung cancer: an international individual patient data meta-analysis. J Thorac Cardiovasc Surg 2010; 139: 1441-1446.

54 Allen JW, Farooq A, O'Brien TF, et al. Quality of surgical resection for nonsmall cell lung cancer in a US metropolitan area. Cancer 2011; 117: 134-142.

55 Verhagen AF, Schoenmakers MC, Barendregt W, et al. Completeness of lung cancer surgery: is mediastinal dissection common practice? Eur J Cardiothorac Surg 2012; 41: 834-838. 
ardinois D, De Leyn P, Van Schil P, et al. ESTS guidelines for intraoperative lymph node staging in non-small cell lung cancer. Eur J Cardiothorac Surg 2006; 30: 787-792.

right

\section{cancer. Lung Cancer Study Group. Ann Thorac Surg 199, 60: 615-622.}

59 Carr SR, Schuchert MJ, Pennathur A, et al. Impact of tumor size on outcomes after anatomic lung resection for stage IA non-small cell lung cancer based on the current staging system. J Thorac Cardiovasc Surg 2012; 143: 390-397.

60 Donahue JM, Morse CR, Wigle DA, et al. Oncologic efficacy of anatomic segmentectomy in stage IA lung cancer patients with T1a tumors. Ann Thorac Surg 2012; 93: 381-387.

61 El-Sherif A, Fernando HC, Santos R, et al. Margin and local recurrence after sublobar resection of non-small cell lung cancer. Ann Surg Oncol 2007; 14: 2400-2405.

62 Kates M, Swanson S, Wisnivesky JP. Survival following lobectomy and limited resection for the treatment of stage I non-small cell lung cancer $<1 \mathrm{~cm}$ in size: a review of SEER data. Chest 2011; 139: 491-496.

63 Sienel W, Stremmel C, Kirschbaum A, et al. Frequency of local recurrence following segmentectomy of stage IA non-small cell lung cancer is influenced by segment localisation and width of resection margins - implications for patient selection for segmentectomy. Eur J Cardiothorac Surg 2007; 31: 522-527.

64 Walker WS, Leaver HA. Immunologic and stress responses following video-assisted thoracic surgery and open pulmonary lobectomy in early stage lung cancer. Thorac Surg Clin 2007; 17: 241-249.

65 Whitson BA, Groth SS, Duval SJ, et al. Surgery for early-stage non-small cell lung cancer: a systematic review of the video-assisted thoracoscopic surgery versus thoracotomy approaches to lobectomy. Ann Thorac Surg 2008; 86: 2016-2018.

66 Flores RM, Park BJ, Dycoco J, et al. Lobectomy by video-assisted thoracic surgery (VATS ) versus thoracotomy for lung cancer. J Thorac Cardiovasc Surg 2009; 138: 11-18.

67 Yan TD, Black D, Bannon PG, et al. Systematic review and meta-analysis of randomized and non-randomized trials on safety and efficacy of video-assisted thoracic surgery lobectomy for early stage non-small-cell lung cancer. J Clin Oncol 2009; 27: 2553-2562.

68 Wolf AS, Richards WG, Jaklitsch MT, et al. Lobectomy versus sublobar resection for small (2 cm or less) non-small cell lung cancers. Ann Thorac Surg 2011; 92: 1819-1823.

69 Cattaneo SM, Park BJ, Wilton AS, et al. Use of video-assisted thoracic surgery for lobectomy in the elderly results in fewer complications. Ann Thorac Surg 2008; 85: 231-235.

70 Petersen RP, Pham D, Burfeind WR, et al. Thoracoscopic lobectomy facilitates the delivery of chemotherapy after resection for lung cancer. Ann Thorac Surg 2007; 83: 1245-1249.

71 Yang CF, D’Amico TA. Thoracoscopic segmentectomy for lung cancer. Ann Thorac Surg 2012; 94: 668-681.

72 Rocco G. One-port (uniportal) video-assisted thoracic surgical resections - a clear advance. J Thorac Cardiovasc Surg 2012; 144: S27-S31.

73 Gonzales-Rivas D, Paradela M, Fernandez R, et al. Uniportal video-assisted thoracoscopic lobectomy: two years of experience. Ann Thorac Surg 2013; 95: 426-432.

74 Morgan JA, Ginsburg ME, Sonett JR, et al. Thoracoscopic lobectomy using robotic technology. Heart Surg Forum 2003; 6: E167-E169.

75 Pardolesi A, Park B, Petrella F, et al. Robotic anatomic segmentectomy of the lung: technical aspects and initial results. Ann Thorac Surg 2012; 94: 929-934.

76 Gharagozloo F, Margolis M, Tempesta B, et al. Robot-assisted lobectomy for early-stage lung cancer: report of 100 consecutive cases. Ann Thorac Surg 2009; 88: 380-384.

77 Park BJ, Flores RM. Cost comparison of robotic, video-assisted thoracic surgery and thoracotomy approaches to pulmonary lobectomy. Thorac Surg Clin 2008; 18: 297-300.

78 Nakata M, Sawada S, Saeki H, et al. Prospective study of thoracoscopic limited resection for ground-glass opacity selected by computed tomography. Ann Thorac Surg 2003; 75: 1601-1605.

79 Lee HY, Lee KS. Ground-glass opacity nodules: histopathology, imaging evaluation and clinical implications. J Thorac Imaging 2011; 26: 106-118.

80 Yoshida Y, Shibata T, Kokubu A. Mutations of the epidermal growth factor receptor gene in atypical adenomatous hyperplasia and bronchioloalveolar carcinoma of the lung. Lung Cancer 2005; 50: 1-8.

81 Ikeda K, Nomori H, Ohba Y, et al. Epidermal growth factor receptor mutations in multicentric lung adenocarcinomas and atypical adenomatous hyperplasias. J Thorac Oncol 2008; 3: 467-471.

82 Depierre A, Westeel V. Overview of the role of neoadjuvant chemotherapy for early stage non-small cell lung cancer. Semin Oncol 2001; 28: Suppl. 14, 29-36

83 Burdett SS, Stewart LA, Rydzewska L. Chemotherapy and surgery versus surgery alone in non-small cell lung cancer. Cochrane Database Syst Rev 2007; 3: CD006157.

84 Berghmans T, Paesmans M, Meert AP, et al. Survival improvement in resectable non-small cell lung cancer with (neo)adjuvant chemotherapy: results of a meta-analysis of the literature. Lung Cancer 2005; 49: 13-23.

85 Nakamura H, Kawasaki N, Taguchi M, et al. Role of preoperative chemotherapy for non-small cell lung cancer: a meta-analysis. Lung Cancer 2006; 54: 325-329.

86 Gilligan D, Nicholson M, Smith I, et al. Preoperative chemotherapy in patients with resectable non-small cell lung cancer: results of the MRC LU22/NVALT 2/EORTC 08012 multicentre randomised trial and update of systematic review. Lancet 2007; 369: 1929-1937.

87 Weder W, Collaud S, Eberhardt WE, et al. Pneumonectomy is a valuable treatment option after neoadjuvant therapy for stage III non-small-cell lung cancer. J Thorac Cardiovasc Surg 2010; 139: 1424-1430.

88 Lim E, Harris G, Patel A, et al. Preoperative versus postoperative chemotherapy in patients with resectable nonsmall cell lung cancer: systematic review and indirect comparison meta-analysis of randomized trials. $J$ Thorac Oncol 2009; 4: 1380-1388.

89 Veeramachaneni NK, Feins RH, Stephenson BJ, et al. Management of stage IIIA non-small cell lung cancer by thoracic surgeons in North America. Ann Thorac Surg 2012; 94: 922-926.

90 van Meerbeeck JP, Kramer GW, Van Schil PE, et al. Randomized controlled trial of resection versus radiotherapy after induction chemotherapy in stage IIIA-N2 non-small-cell lung cancer. J Natl Cancer Inst 2007; 99: 442-450. 
91 Cerfolio RJ, Maniscalo L, Bryant AS. The treatment of patients with stage IIIA non-small cell lung cancer from N2 disease: who returns to the surgical arena and who survives. Ann Thorac Surg 2008; 86: 912-920.

92 Riquet M, Assouad J, Bagan P, et al. Skip mediastinal lymph node metastasis and lung cancer: a particular N2 subgroup with a better prognosis. Ann Thorac Surg 2005; 79: 225-233.

93 Goldstraw P, Mannam GC, Kaplan DK, et al. Surgical management of non-small-cell lung cancer with ipsilateral mediastinal node metastasis (N2 disease). J Thorac Cardiovasc Surg 1994; 107: 19-27.

94 Naruke T, Goya T, Tsuchiya R, et al. The importance of surgery in non-small cell carcinoma of the lung with mediastinal lymph node metastasis. Ann Thorac Surg 1988; 46: 603-610.

95 Martini N, Kris MG, Flehinger BJ, et al. Preoperative chemotherapy of stage IIIA (N2) non-small cell lung cancer: the Sloan-Kettering experience with 136 patients. Ann Thorac Surg 1993; 55: 1365-1373.

96 Rosell R, Gómez-Codina J, Camps C, et al. A randomized trial comparing preoperative chemotherapy plus surgery with surgery alone in patients with non-small-cell lung cancer. N Engl J Med 1994; 330: 153-158.

97 Roth JA, Fossella F, Komaki R, et al. A randomized trial comparing perioperative chemotherapy and surgery with surgery alone in resectable stage IIIA non-small-cell lung cancer. J Natl Cancer Inst 1994; 86: 673-680.

98 Albain KS, Swann RS, Rusch VW, et al. Radiotherapy plus chemotherapy with or without surgical resection for stage III non-small-cell lung cancer: a phase III randomised controlled trial. Lancet 2009; 374: 379-386.

99 Thomas M, Rübe C, Hoffknecht P, et al. Effect of preoperative chemoradiation in addition to preoperative chemotherapy: a randomised trial in stage III non-small-cell lung cancer. Lancet Oncol 2008; 9: 636-648.

100 Kim AW, Boffa DJ, Wang Z, et al. An analysis, systematic review and meta-analysis of the perioperative mortality after neoadjuvant therapy and pneumonectomy for non-small cell lung cancer. J Thorac Cardiovasc Surg 2012; 143: 55-63.

101 Shah AA, Berry MF, Tzao C, et al. Induction chemoradiation is not superior to induction chemotherapy alone in stage IIIA lung cancer. Ann Thorac Surg 2012; 93: 1807-1812.

102 Kirsh MM, Sloan H. Mediastinal metastases in bronchogenic carcinoma: influence of postoperative irradiation, cell type and location. Ann Thorac Surg 1982; 33: 459-463.

103 Effects of postoperative mediastinal radiation on completely resected stage II and III epidermoid cancer of the lung. The lung cancer study group. N Engl J Med 1986; 315: 1377-1381.

104 Postoperative radiotherapy for non-small cell lung cancer. PORT meta-analysis trialists group. Cochrane Database Syst Rev 2005; 18: CD002142.

105 Saynak M, Higginson DS, Morris DE, et al. Current status of postoperative radiation for non-small-cell lung cancer. Semin Radiat Oncol 2010; 20: 192-200.

106 Le Péchoux C. Role of postoperative radiotherapy in resected non-small cell lung cancer: a reassessment based on new data. Oncologist 2011; 16: 672-681.

107 Mazeron R, Le Péchoux C, Bruna A, et al. Irradiation prophylactique cérébrale dans les cancers bronchopulmonaires non à petites cellules. [Prophylactic cranial irradiation in non-small cell lung cancer]. Cancer Radiother 2007; 11: 84-91.

108 Le Péchoux C, Al Mohkles H, Dhermain F. Place actuelle de l'irradiation prophylactique cerebrale. [Present role of prophylactic cranial irradiation]. Bull Cancer 2013; 100: 35-43.

109 Stupp R, Mayer M, Kann R, et al. Neoadjuvant chemotherapy and radiotherapy followed by surgery in selected patients with stage IIIB non-small-cell lung cancer: a multicentre phase II trial. Lancet Oncol 2009; 10: 785-793.

110 Stoelben E, Ludwig C. Chest wall resection for lung cancer: indications and techniques. Eur J Cardiothorac Surg 2009; 35: 450-456.

111 Doddoli C, D'Journo B, Le Pimpec-Barthes F, et al. Lung cancer invading the chest wall: a plea for en-bloc resection but the need for new treatment strategies. Ann Thorac Surg 2005; 80: 2032-2040.

112 Roviaro G, Varoli F, Grignani F, et al. Non-small cell lung cancer with chest wall invasion: evolution of surgical treatment and prognosis in the last 3 decades. Chest 2003; 123: 1341-1347.

113 Chapelier A, Fadel A, Macchiarini P, et al. Factors affecting long-term survival after en-bloc resection of lung cancer invading the chest wall. Eur J Cardiothorac Surg 2000; 18: 513-518.

114 Rocco G, Rendina EA, Meroni A, et al. Prognostic factors after surgical treatment of lung cancer invading the diaphragm. Ann Thorac Surg 1999; 68: 2065-2068.

115 Kawaguchi K, Miyaoka E, Asamura H, et al. Modern surgical results of lung cancer involving neighboring structures: a retrospective analysis of 531 pT3 cases in a Japanese Lung Cancer Registry Study. J Thorac Cardiovasc Surg 2012; 144: 431-437.

116 Riquet M, Lang-Lazdunski L. Results of surgical treatment of lung cancer involving the diaphragm. $J$ Thorac Cardiovasc Surg 2001; 121: 1224-1226.

117 Yokoi K, Tsuchiya R, Mori T, et al. Results of surgical treatment of lung cancer involving the diaphragm. J Thorac Cardiovasc Surg 2000; 120: 799-805.

118 Souilamas R, Hidden G, Riquet M. Mediastinal lymphatic efferents from the diaphragm. Surg Radiol Anat 2001; 23: $159-162$.

119 Martini N, Yellin A, Ginsberg RJ, et al. Management of non-small cell lung cancer with direct mediastinal involvement. Ann Thorac Surg 1994; 58: 1447-1451.

120 Riquet M, Lang-Lazdunski L, Le Pimpec Barthes F, et al. Characteristics and prognosis of resected T3 non-small cell lung cancer. Ann Thorac Surg 2002; 73: 253-258.

121 Pitz CC, de la Rivière AB, van Swieten HA, et al. Surgical treatment of Pancoast tumours. Eur J Cardiothorac Surg 2004; 26: 202-208.

122 Dartevelle PG, Chapelier AR, Macchiarini P, et al. Anterior transcervical-thoracic approach for radical resection of lung tumors invading the thoracic inlet. J Thorac Cardiovasc Surg 1993; 105: 1025-1034.

123 Grunenwald D, Spaggiari L. Transmanubrial osteomuscular sparing approach for apical chest tumors. Ann Thorac Surg 1997; 63: 563-566.

124 Fischer S, Darling G, Pierre AF, et al. Induction chemoradiation therapy followed by surgical resection for nonsmall cell lung cancer (NSCLC) invading the thoracic inlet. Eur J Cardiothorac Surg 2008; 33: 1129-1134.

125 Rusch VW, Giroux DJ, Kraut MJ, et al. Induction chemoradiation and surgical resection for superior sulcus nonsmall-cell lung carcinomas: long-term results of Southwest Oncology Group Trial 9416 (intergroup trial 0160). J Clin Oncol 2007; 25: 313-318. 
126 Pourel N, Santelmo N, Naafa N, et al. Concurrent cisplatin/etoposide plus 3D-conformal radiotherapy followed by surgery for stage IIB (superior sulcus T3N0)/III non-small cell lung cancer yields a high rate of pathological complete response. Eur J Cardiothorac Surg 2008; 33: 829-836.

127 Kappers I, van Sandick JW, Burgers JA, et al. Results of combined modality treatment in patients with non-small cell lung cancer of the superior sulcus and the rationale for surgical resection. Eur J Cardiothorac Surg 2009; 36: 741-746.

128 Marra A, Eberhardt W, Pöttgen C, et al. Induction chemotherapy, concurrent chemoradiation and surgery for Pancoast tumour. Eur Respir J 2007; 29: 117-126.

129 Kwong KF, Edelman MJ, Suntharalingam M, et al. High-dose radiotherapy in trimodality treatment of Pancoast tumors results in high pathologic complete response rates and excellent long-term survival. $J$ Thorac Cardiovasc Surg 2005; 129: 1250-1257.

130 Regnard JF, Perrotin C, Giovannetti R, et al. Resection for tumors with carinal involvement: technical aspects, results and prognostic factors. Ann Thorac Surg 2005; 80: 1841-1846.

131 Yildizeli B, Dartevelle PG, Fadel E, et al. results of primary surgry with T4 non-small cell lung cancer during a 25year period in a single center: the benefit is worth the risk. Ann Thorac Surg 2008; 86: 1065-1075.

132 Rea F, Marulli G, Schiavon M, et al. Tracheal sleeve pneumonectomy for non-small cell lung cancer (NSCLC): short and long-term results in a single institution. Lung Cancer 2008; 61: 202-208.

133 Jiang F, Xu L, Yuan F, et al. Carinal resection and reconstruction in surgical treatment of bronchogenic carcinoma with carinal involvement. $J$ Thorac Oncol 2009; 4: 1375-1379.

134 Mitchell JD, Mathisen DJ, Wright CD, et al. Resection for bronchogenic carcinoma involving the carina: long-term results and effect of nodal status on outcome. J Thorac Cardiovasc Surg 2001; 121: 465-471.

135 Muralidaran A, Detterbeck FC, Boffa DJ, et al. Long-term survival after lung resection for non-small cell lung cancer with circulatory bypass: a systematic review. J Thorac Cardiovasc Surg 2011; 142: 1137-1142.

136 Wiebe K, Baraki H, Macchiarini P, et al. Extended pulmonary resections of advanced thoracic malignancies with support of cardiopulmonary bypass. Eur J Cardiothorac Surg 2006; 29: 571-577.

137 de Perrot M, Fadel E, Mussot S, et al. Resection of locally advanced (T4) non-small cell lung cancer with cardiopulmonary bypass. Ann Thorac Surg 2005; 79: 1691-1696.

138 Spaggiari L, D'Aiuto M, Veronesi G, et al. Extended pneumonectomy with partial resection of the left atrium, without cardiopulmonary bypass, for lung cancer. Ann Thorac Surg 2005; 79: 234-240.

139 Ratto GB, Costa R, Vassallo G, et al. Twelve-year experience with left atrial resection in the treatment of non-small cell lung cancer. Ann Thorac Surg 2004; 78: 234-237.

140 Shargall Y, de Perrot M, Keshavjee S, et al. 15 years single center experience with surgical resection of the superior vena cava for non-small cell lung cancer. Lung Cancer 2004; 45: 357-363.

141 Spaggiari L, Leo F, Veronesi G, et al. Superior vena cava resection for lung and mediastinal malignancies: a singlecenter experience with 70 cases. Ann Thorac Surg 2007; 83: 223-229.

142 Shintani Y, Ohta M, Minami M, et al. Long-term graft patency after replacement of the brachiocephalic veins combined with resection of mediastinal tumors. J Thorac Cardiovasc Surg 2005; 129: 809-812.

143 Dartevelle PG, Chapelier AR, Pastorino U, et al. Long-term follow-up after prosthetic replacement of the superior vena cava combined with resection of mediastinal-pulmonary malignant tumors. J Thorac Cardiovasc Surg 1991; 102: $259-265$.

144 Spaggiari L, Regnard JF, Magdeleinat P, et al. Extended resections for bronchogenic carcinoma invading the superior vena cava system. Ann Thorac Surg 2000; 69: 233-236.

145 Fadel E, Chapelier A, Bacha E, et al. Subclavian artery resection and reconstruction for thoracic inlet cancers. J Vasc Surg 1999; 29: 581-588.

146 Nomori H, Hirotani T, Watanabe K, et al. Extended resection of lung cancer invading the left subclavian artery by using cardiopulmonary bypass. Ann Thorac Cardiovasc Surg 2005; 11: 211-213.

147 Grunenwald DH, Mazel C, Girard P, et al. Radical en bloc resection for lung cancer invading the spine. J Thorac Cardiovasc Surg 2002; 123: 271-279.

148 Schirren J, Dönges T, Melzer M, et al. En bloc resection of non-small cell lung cancer invading the spine. Eur $J$ Cardiothorac Surg 2011; 40: 647-654.

149 Fadel E, Missenard G, Court C, et al. Long-term outcomes of en bloc resection of non-small cell lung cancer invading the thoracic inlet and spine. Ann Thorac Surg 2011; 92: 1024-1030.

150 Ankaru M, Waddell TK, de Perrot M, et al. Induction chemoradiotherapy facilitates radical resection of T4 nonsmall cell lung cancer invading the spine. J Thorac Cardiovasc Surg 2009; 137: 441-447.

151 Rami-Porta R, Ball D, Crowley J, et al. The IASLC Lung Cancer Staging Project: proposals for the revision of the T descriptors in the forthcoming (seventh) edn of the TNM classification for lung cancer. $J$ Thorac Oncol 2007; 2: 593-602.

152 Bryant AS, Pereira SJ, Miller DL, et al. Satellite pulmonary nodule in the same lobe (T4N0) should not be staged as IIIB non-small cell lung cancer. Ann Thorac Surg 2006; 82: 1808-1013.

153 Nagai K, Sohara Y, Tsuchiya R, et al. Prognosis of resected non-small cell lung cancer patients with intrapulmonary metastases. J Thorac Oncol 2007; 2: 282-286.

154 Pennathur A, Lindeman B, Ferson P, et al. Surgical resection is justified in non-small cell lung cancer patients with node negative T4 satellite lesions. Ann Thorac Surg 2009; 87: 893-899.

155 Battafarano RJ, Meyers BF, Guthrie TJ, et al. Surgical resection of multifocal non-small cell lung cancer is associated with prolonged survival. Ann Thorac Surg 2002; 74: 988-993.

156 Sculier JP. Nonsmall cell lung cancer. Eur Respir Rev 2013; 22: 33-36.

157 De Ruysscher D, Wanders R, van Baardwijk A, et al. Radical treatment of non-small cell lung cancer patients with synchronous oligometastases: long-term results of a prospective phase II trial (NCT 01282450). J Thorac Oncol 2012; 7: 1547-1555.

158 Kawabe T, Phi JH, Yamamoto M, et al. Treatment of brain metastasis from lung cancer. Prog Neurol Surg 2012; 25 : $148-155$.

159 Bonnette P, Puyo P, Gabriel C, et al. Surgical management of non-small cell lung cancer with synchronous brain metastases. Chest 2001; 119: 1469-1475. 
160 Billing PS, Miller DL, Allen, et al. Surgical treatment of primary lung cancer with synchronous brain metastases. J Thorac Cardiovasc Surg 2001; 122: 548-553.

161 Raz DJ, Lanuti M, Gaissert HC, et al. Outcomes of patients with isolated adrenal metastasis from non-small cell lung carcinoma. Ann Thorac Surg 2011; 92: 1788-1792.

162 Mercier O, Fadel E, de Perrot M, et al. Surgical treatment of solitary adrenal metastasis from non-small cell lung cancer. J Thorac Cardiovasc Surg 2005; 130: 136-140.

163 Porte H, Siat J, Guibert B, et al. Resection of adrenal metastases from non-small cell lung cancer: a multicenter study. Ann Thorac Surg 2001; 71: 981-985.

164 Lucchi M, Dini P, Ambrogi MC, et al. Metachronous adrenal masses in resected non-small cell lung cancer patients: therapeutic implications of laparoscopic adrenalectomy. Eur J Cardiothorac Surg 2005; 27: 753-756.

165 Hunt I, Rankin SC, Lang-Lazdunski L. Combined lung resection and transdiaphragmatic adrenalectomy in patients with non-small cell lung cancer and homolateral solitary adrenal metastasis. Eur J Cardiothorac Surg 2006; 30: 194-195.

166 Tanvetyanon T, Robinson LA, Schell MJ, et al. Outcomes of adrenalectomy for isolated synchronous versus metachronous adrenal metastases in non-small-cell lung cancer: a systematic review and pooled analysis. J Clin Oncol 2008; 26: 1142-1147.

167 Pfannschmidt J, Schlolaut B, Muley T, et al. Adrenalectomy for solitary adrenal metastases from non-small cell lung cancer. Lung Cancer 2005; 49: 203-207.

168 Salah S, Tanvetyanon T, Abbasi S. Metastasectomy for extra-cranial extra-adrenal non-small cell lung cancer solitary metastases: systematic review and analysis of reported cases. Lung Cancer 2012; 75: 9-14.

169 Mordant P, Arame A, Foucault C, et al. Surgery for metastatic pleural extension of non-small cell lung cancer. Eur J Cardiothorac Surg 2011; 40: 1444-1449.

170 Okamoto T, Iwata T, Mizobuchi T, et al. Pulmonary resection for lung cancer with malignant pleural disease first detected at thoracotomy. Eur J Cardiothorac Surg 2012; 41: 25-30.

171 Voltolini L, Paladini P, Luzzi L, et al. Iterative surgical resections for local recurrent and second primary bronchogenic carcinoma. Eur J Cardiothorac Surg 2000; 18: 529-534.

172 Tabutin M, Couraud S, Guibert B, et al. Completion pneumonectomy in patients with cancer: postoperative survival and mortality factors. J Thorac Oncol 2012; 7: 1556-1562.

173 Guggino G, Doddoli C, Barlesi F, et al. Completion pneumonectomy in cancer patients: experience with 55 cases. Eur J Cardiothorac Surg 2004; 25: 449-455.

174 Cardillo G, Galetta D, van Schil P, et al. Completion pneumonectomy: a multi-centre international study on 165 patients. Eur J Cardiothorac Surg 2012; 42: 405-409.

175 Chataigner O, Fadel E, Yildizeli B, et al. Factors affecting early and long-term outcomes after completion pneumonectomy. Eur J Cardiothorac Surg 2008; 33: 837-843.

176 Dominguez-Ventura A, Cassivi SD, Allen MS, et al. Lung cancer in octogenerians: factors affecting long-term survival following resection. Eur J Cardiothorac Surg 2007; 32: 370-374.

177 Okami J, Higashiyama M, Asamura $\mathrm{H}$, et al. Pulmonary resection in patients aged 80 years or over with clinical stage I non-small cell lung cancer: prognostic factors for overall survival and risk factors for postoperative complications. J Thorac Oncol 2009; 4: 1247-1253.

178 Matsuoka H, Okada M, Sakamoto T, et al. Complications and outcomes after pulmonary resection for cancer in patients 80 to 89 years of age. Eur J Cardiothorac Surg 2005; 28: 380-383.

179 McKenna RJ Jr. Thoracoscopic lobectomy with mediastinal sampling in 80-year old patients. Chest 1994; 106: 1902-1904.

180 Cadranel J, Garfield D, Lavolé A, et al. Lung cancer in HIV infected patients: facts, questions and challenges. Thorax 2006; 61: 1000-1008.

181 Hakimian R, Fang H, Thomas L, et al. Lung cancer in HIV-infected patients in the era of highly active antiretroviral therapy. J Thorac Oncol 2007; 2: 268-272.

182 Sridhar KS, Flores MR, Raub WA Jr, et al. Lung cancer in patients with human immunodeficiency virus infection compared with historic control subjects. Chest 1992; 102: 1704-1708.

183 Hooker CM, Meguid RA, Hulbert A, et al. Human immunodeficiency virus infection as a prognostic factor in surgical patients with non-small cell lung cancer. Ann Thorac Surg 2012; 93: 405-412.

184 Mitchell JD, Bishop A, Cafaro A, et al. Anatomic lung resection for nontuberculous mycobacterial disease. Ann Thorac Surg 2008; 85: 1887-1892.

185 Morano MT, Araújo AS, Nascimento FB, et al. Preoperative pulmonary rehabilitation versus chest physical therapy in patients undergoing lung cancer resection: a pilot randomized controlled trial. Arch Phys Med Rehabil 2013; 94: 53-58.

186 Benzo R, Wigle D, Novotny P, et al. Preoperative pulmonary rehabilitation before lung cancer resection: results from two randomized studies. Lung Cancer 2011; 74: 441-445.

187 Jordan S, Evans TW. Predicting the need for intensive care following lung resection. Thorac Surg Clin 2008; 18: 61-69.

188 Martin J. Lung resection in the pulmonary-compromised patient. Thorac Surg Clin 2004; 14: 157-162.

189 Bach PB, Cramer LD, Schrag D, et al. The influence of hospital volume on survival after resection for lung cancer. N Engl J Med 2001; 345: 181-188.

190 Sioris T, Sihvo E, Sankila R, et al. Effect of surgical volume and hospital type on outcome in non-small cell lung cancer surgery: a Finnish population-based study. Lung Cancer 2008; 59: 119-125.

191 Cheung MC, Hamilton K, Sherman R, et al. Impact of teaching facility status and high-volume centers on outcomes for lung cancer resection: an examination of 13,469 surgical patients. Ann Surg Oncol 2009; 16: 3-13.

192 Lien YC, Huang MT, Lin HC. Association between surgeon and hospital volume and in-hospital fatalities after lung cancer resections: the experience of an Asian country. Ann Thorac Surg 2007; 83: 1837-1843.

193 von Meyenfeldt EM, Gooiker GA, van Gijn W, et al. The relationship between volume or surgeon specialty and outcome in the surgical treatment of lung cancer: a systematic review and meta-analysis. J Thorac Oncol 2012; 7: $1170-1178$

194 Shaw P, Agarwal R. Pleurodesis for malignant pleural effusions. Cochrane Database Syst Rev 2004; 1: CD002916.

195 Stefani A, Natali P, Casali C, et al. Talc poudrage versus talc slurry in the treatment of malignant pleural effusion. A prospective comparative study. Eur J Cardiothorac Surg 2006; 30: 827-832. 
196 Cardillo G, Facciolo F, Carbone L, et al. Long-term follow-up of video-assisted talc pleurodesis in malignant recurrent pleural effusions. Eur J Cardiothorac Surg 2002; 21: 302-305.

197 Hunt BM, Farivar AS, Vallières E, et al. Thoracoscopic talc versus tunneled pleural catheters for palliation of malignant pleural effusions. Ann Thorac Surg 2012; 94: 1053-1057.

198 Allen KB, Faber LP, Warren WH, et al. Pericardial effusion: subxiphoid pericardiostomy versus percutaneous catheter drainage. Ann Thorac Surg 1999; 67: 437-440.

199 Maruyama R, Yokoyama H, Seto T, et al. Catheter drainage followed by the instillation of bleomycin to manage malignant pericardial effusion in non-small cell lung cancer: a multi-institutional phase II trial. $J$ Thorac Oncol 2007; 2: 65-68.

200 Kunitoh H, Tamura T, Shibata T, et al. A randomised trial of intrapericardial bleomycin for malignant pericardial effusion with lung cancer (JCOG9811). Br J Cancer 2009; 100: 464-469.

201 O'Brien PK, Kucharczuk JC, Marshall MB, et al. Comparative study of subxiphoid versus video-thoracoscopic pericardial "window". Ann Thorac Surg 2005; 80: 2013-2019.

202 Geissbühler K, Leiser A, Fuhrer J, et al. Video-assisted thoracoscopic pericardial fenestration for loculated or recurrent effusions. Eur J Cardiothorac Surg 1998; 14: 403-408.

203 Gompelmann D, Eberhardt R, Herth FJ. Advanced malignant lung disease: what the specialist can offer. Respiration 2011; 82: 111-123.

204 Santos RS, Raftopoulos Y, Keenan RJ, et al. Bronchoscopic palliation of primary lung cancer: single or multimodality therapy? Surg Endosc 2004; 18: 931-936.

205 McGrath EE, Warriner D, Anderson P. The insertion of self expanding metal stents with flexible bronchoscopy under sedation for malignant tracheobronchial stenosis: a single-center retrospective analysis. Arch Bronconeumol 2012; 48: 43-48.

206 Shin JH, Song HY, Ko GY, et al. Esophagorespiratory fistula: long-term results of palliative treatment with covered expandable metallic stents in 61 patients. Radiology 2004; 232: 252-259.

207 Lanciego C, Pangua C, Chacón JI, et al. Endovascular stenting as the first step in the overall management of superior vena cava syndrome. AJR Am J Roentgenol 2009; 193: 549-558. 